\title{
Understanding the Role of Sodium Lauryl Sulfate on the Biorelevant Solubility of a Combination of Poorly Water-Soluble Drugs Using High Throughput Experimentation and Mechanistic Absorption Modeling
}

\author{
Matthew N. Bahr ${ }^{1,3}$, Dimple Modi ${ }^{1,3}$, Sarsvatkumar Patel ${ }^{1}$, Gossett Campbell ${ }^{1}$, Gregory Stockdale ${ }^{2}$ \\ ${ }^{1}$ GlaxoSmithKline, Medicinal Science \& Technology and ${ }^{2}$ CMC Statistics, Pharmaceutical Research and Development, \\ Collegeville, Pennsylvania PA; ${ }^{3}$ University of the Sciences, Philadelphia College of Pharmacy, Philadelphia, PA 19104, \\ USA.
}

Received, Feb 27, 2019; Revised, May 25, 2019; Accepted, June 12, 2019; Publishes, June 15, 2019.

\begin{abstract}
This study investigates the influence of surfactant sodium lauryl sulfate (SLS) on the solubility of poorly-water soluble drug substances, model Compound $\mathrm{X}$ and Compound $\mathrm{Y}$, used in a fixed dose combination oral solid dosage form. To determine the impact of SLS concentration on the solubility of compounds X and Y, we experimentally determined the critical micelle concentration (CMC) of SLS in water, simulated gastric fluid (SGF), and fed state simulated intestinal fluid (FeSSIF) in the presence of Compound X and Compound Y using $\mathrm{UV} /$ Visible spectrophotometry at $25^{\circ} \mathrm{C}$. The aggregation of SLS was characterized by calculating the standard Gibbs free energy of micellization in all the media investigated. To enhance the understanding of SLS aggregation, high throughput experiments and in-vivo mechanistic modelling were used to determine the effect of increasing levels of SLS on the solubility of compounds X and Y as both single agent and combination products to be formulated into a suitable oral solid dosage form. Micellar formation of SLS is a spontaneous process as shown by the negative values of the standard free energy of micellization. The CMC of SLS in the various media investigated in the presence of compounds $\mathrm{X}$ and $\mathrm{Y}$ decreases in the following order: water $>$ FeSSIF> SGF. However, the aggregation of SLS in the various media is overall more spontaneous in the following order: $\mathrm{SGF}>\mathrm{FeSSIF}>$ water. Using high throughput experimentation and in-vivo mechanistic modelling, it was determined that a combination oral solid product of compounds $\mathrm{X}$ and $\mathrm{Y}$ will have optimum solubility and in-vivo absorption if $2 \mathrm{mg}$ of SLS was used in the oral solid dosage form. The results obtained from this study will help broaden the understanding of the micellization process involving SLS and poorly-water soluble drugs used in combination oral solid dosage forms.
\end{abstract}

\section{INTRODUCTION}

The solubility of drug substances is paramount to the design, development, manufacturability and biopharmaceutics of a dosage form. During the developability phase, a lead drug substance identified through candidate selection is characterized for its physicochemical properties such as solubility, pKa, bulk/tap density (flowability), permeability, $\log \mathrm{P}, \log \mathrm{D}$ and others. Using the information gained from solubility and permeability testing, the drug substance is classified using the Biopharmaceutical Classification System (BCS) as class I (high permeability-high solubility), class II (high permeability-low solubility), class III (low permeability-high solubility) or class IV (low permeability-low solubility) $(1,2)$. It has previously been reported in literature that although only $33 \%$ of currently marketed drugs demonstrate low solubility and high permeability, $70 \%$ of new molecules fell into the Class II category (3). Therefore, the early phase characterization of the physicochemical properties of the drug substance is crucial to the selection of the right dosage form, excipients, and manufacturing process. Pharmaceutical companies have been dealing with the challenges of poor oral drug absorption, to include poor aqueous solubility, for decades (4-6). However, researchers from pharmaceutical industry and academia have found and implemented innovative solutions and technologies to manage the challenge. These approaches include particle size reduction $(7,8)$, salt screening (9), co-crystal formation (10), polymer complexation (11), prodrug formation (12), micellization (13), solid dispersions (14-18), self-

Corresponding Author: Matthew N. Bahr, Medicinal Science \& Technology, Pharmaceutical Research and Development GlaxoSmithKline, 1250 S. Collegeville Rd., Collegeville, Pennsylvania, USA, E-mail: matthew.n.bahr@gsk.com 
emulsifying drug delivery system (SEDDS) $(19,20)$, supercritical fluid (SCF) technology (21), and surfactant systems (to improve wettability) $(22,23)$.

In this paper, we investigated the effect of anionic surfactant sodium lauryl sulfate (SLS) on the enhancement of the solubility of two model drug substances that are poorly water-soluble; Compound $\mathrm{X}$ and Compound Y. The main focus of this work was to determine if the level of SLS for optimum solubility in biorelevant media of the individual compounds differs or remains the same when used as a fixed dose combination product. Model Compound $\mathrm{X}$, an anhydrous crystalline form, molecular weight $378 \mathrm{~g} / \mathrm{mol}$, has a $\mathrm{pKa}$ of 4.0 , is non-hygroscopic and is a BCS class II molecule. Model Compound Y, an anhydrous crystalline form, molecular weigh 389 $\mathrm{g} / \mathrm{mol}$, is a non-ionizable molecule (no $\mathrm{pKa}$ ), is nonhygroscopic and is also a BCS class II molecule. SLS is used as a solubilizing agent for both small and large molecules due to its effectiveness of enhancing solubility through micellular dissolution. SLS has a hydrophilic sulfate group in the head and hydrophobic dodecyl group in the tail which allows it to aggregate and form micelles above the critical micelle concentration (CMC) (24).

To the best of our knowledge, despite published literature on the use of SLS as a solubilizer, there is no information on the optimum level of SLS to use in a fixed dose combination product for poorly water-soluble drug substances. Therefore, in this study we aim to investigate the aggregation behavior of surfactant SLS in enhancing the biorelevant solubility of model Compound $\mathrm{X}$ and Compound $\mathrm{Y}$ through high throughput experimentation and UVVis spectrophotometry. Additionally, the physicochemical and biopharmaceutical properties of the drug substances were used to generate simulation models for in-vivo absorption. The CMC of SLS was determined in simulated gastric fluid (SGF), fed state simulated intestinal fluid (FeSSIF) and water for the individual drug substance as well as the combined drug substances. The micellization of the drug substances (individual and in combination) was further understood by calculating thermodynamic properties of Gibbs free energy. The data indicated that CMC of SLS in presence of Compounds $\mathrm{X}$ and $\mathrm{Y}$ decreases in the following order: water $>$ FeSSIF $>$ SGF. The negative values of the Gibbs free energy of micellization indicated that the aggregation process is spontaneous. The aggregation of SLS in the various media is overall more spontaneous in the following order:
SGF $>$ FeSSIF $>$ water. In SGF, the maximum solubility of both Compounds $\mathrm{X}$ and $\mathrm{Y}$ used in combination was achieved with $2 \mathrm{mg}$ SLS, which is different compared to the solubility of Compound X alone or Compound Y alone in SGF where a gradual increase in solubility was observed as a function of SLS concentration. Therefore, in designing a fixed dose combination (FDC) oral solid product containing both Compound $\mathrm{X}$ and Compound $\mathrm{Y}, 2$ $\mathrm{mg}$ of SLS would be preferred to ensure maximum dissolution in the stomach and ultimately an increase in intestinal absorption. The significance of this work is that formulation scientists can apply this approach to identify the right level of experimentation and techniques to better understand and determine the optimum level of surfactant to use in a single-drug oral solid product and a fixed dose combination oral solid product.

\section{MATERIALS \& METHODS}

\section{MATERIALS}

Compound $\mathrm{X}$, a model drug substance, is manufactured by GlaxoSmithKline. This crystalline compound is a BCS Class II drug (low solubility and high permeability). Compound $\mathrm{Y}$ is an externally sourced crystalline drug substance that is nonionizable across the $\mathrm{pH}$ range and is a BCS Class II drug. Sodium lauryl sulfate (SLS) is a polymeric anionic surface acting agent (surfactant) used in pharmaceutical applications and serves as a stabilizing solubilizer in drug formulations. The SLS used in this study was Texapon K12P Fine Kolliphor, sourced from BASF (Ludwigshafen, Germany).

Fed State Simulated Intestinal Fluid (FeSSIF) was prepared by GlaxoSmithKline using $11.2 \mathrm{~g}$ of FeSSIF powder into a buffer solution of $4.04 \mathrm{~g}$ $\mathrm{NaOH}$ pellets, anhydrous $3.44 \mathrm{~g} \mathrm{Na}_{2} \mathrm{HPO}_{4}$ powder and $6.19 \mathrm{~g} \mathrm{NaCl}$ powder dissolved into $0.9 \mathrm{~L}$ of purified water. $\mathrm{pH}$ was adjusted to 6.5 , with purified water added to make up $1 \mathrm{~L}$ of buffer solution. Fasted State Simulated Intestinal Fluid (FaSSIF) was prepared by GlaxoSmithKline using $2.24 \mathrm{~g}$ FaSSIF powder into a buffer solution of $0.42 \mathrm{~g} \mathrm{NaOH}$ pellets, $3.44 \mathrm{~g} \mathrm{Na}_{2} \mathrm{HPO}_{4}$ powder and $6.19 \mathrm{~g} \mathrm{NaCl}$ powder dissolved into $0.9 \mathrm{~L}$ of purified water. $\mathrm{pH}$ was adjusted to 6.5, with purified water added to make up $1 \mathrm{~L}$ of buffer solution. Simulated Gastric Fluid (SGF) was prepared by GlaxoSmithKline using 2.0 $\mathrm{g}$ of $\mathrm{NaCl}$ and $3.2 \mathrm{~g}$ of pepsin into $7 \mathrm{~mL}$ of $\mathrm{HCl}$. 
Purified water was added to approach $1 \mathrm{~L}$ of volume. $\mathrm{pH}$ was adjusted to 1.6 with purified water added to make up $1 \mathrm{~L}$ of buffered solution. HPLC Plus grade water was procured from Sigma Aldrich.

\section{METHODS}

\section{DISSOLUTION METHOD}

The dissolution method for Compound $\mathrm{X}$ and Compound Y drug substances use USP Apparatus 2 with $1000 \mathrm{ml}$ of $0.5 \% \mathrm{w} / \mathrm{v}$ SLS in water, and a paddle speed of $50 \mathrm{rpm}$. Dissolution samples are analyzed using a HPLC method with UV detection.

\section{AUTOMATED PLATFORMS \\ EXPERIMENTAL METHOD}

Both compounds and the excipient used in this study were placed into Mettler-Toledo QH012-LNMP powder dispense heads and were dispensed into 1 $\mathrm{mL}$ glass vials using a Mettler-Toledo QX96 automated powder dispensing platform (MettlerToledo GmbH, Greifensee, Switzerland). The $1 \mathrm{~mL}$ glass vials were prepared on a 96-well plate commonly used in high throughput experimentation.

$500 \mu \mathrm{L}$ of each liquid was dispensed into its respective vial in replicates of three, using the syringe pump and liquid dispense needles on an Unchained Labs Freeslate CM3 automation platform (Unchained Labs, Pleasanton CA, USA). Stir dowels were added to each vial to enhance the mixing and to ensure proper wetting of the powders in the liquids. The plate was then sealed with a lid and stirred at $25^{\circ} \mathrm{C}$ and $500 \mathrm{rpm}$ for one hour and eight hours. Following the allotted mixing time, the samples were filtered through a $0.45 \mu \mathrm{m}$ HDPE membrane. The filtered supernatant was obtained and placed on an HPLC for solubility analysis.

\section{AUTOMATED HPLC METHOD}

The concentration of the solubility samples was analyzed on an Agilent 1100 HPLC (Agilent Technologies, Santa Clara CA, USA). Both compounds have chromophores, and are detectable using a single analytical HPLC method which was developed to provide good separation between the two compounds at unique wavelengths (detectable by $\mathrm{DAD}$ ) and retention times, with a total run time of 2 minutes and flow rate of $2 \mathrm{~mL} / \mathrm{min}$. Through this analytical HPLC method development, it was determined that the absorbance wavelengths for Compound X and Compound Y were $262 \mathrm{~nm}$ and $285 \mathrm{~nm}$ respectively. A Zorbax Eclipse $3.5 \mu \mathrm{m}$ SB-
C18 reverse-phase column $(4.6 \times 150 \mathrm{~mm})$ was selected for the HPLC method. Calibration standards were prepared for each compound, and calibration curves were prepared with correlation values of 0.999 or higher.

\section{METHOD FOR CMC DETERMINATION UV-Visible Spectrophotometry}

An Agilent 8453 UV-Vis Spectrophotometer with a model G1811A XY-Autosampler was used with a QS $1.00 \mathrm{~cm}$ flowthrough cuvette to generate UV absorbance for the various samples. Glass test tubes containing the samples were placed in designated holders in the unit and the instrument was operated automatically to test the samples and generate the data.

\section{Kruss Tensiometer}

A Kruss K100 force tensiometer was used to generate the surface tension data. Samples were placed into a syringe and needle assembly which is then placed into the instrument chamber. The droplet size was adjusted manually to obtain a suitable size droplet for surface tension measurements. The instrument was then set to operate automatically to generate the surface tension results for the media.

\section{Sample Preparation}

The samples for CMC determination were prepared from a bulk solution of $20 \mathrm{mM}$ SLS concentration media (water, SGF, and FeSSIF) using the dilution scheme delineated in Table 1. The target quantity of the drug substances (Compound $\mathrm{X}$ and $\mathrm{Y}$ ) was preweighed into scintillation vials using the QX96 high throughput automated powder dispensing platform. Subsequently, the final volume of the prepared media with SLS was added to the drug substance vial and slightly agitated overnight. Each sample was placed into three test tubes and UV absorbance was collected at the respective wavelenghts for the two model compounds. The average absorbance value of the triplicate measurements was used to determine the CMC of SLS in the media containing Compounds X, Y, and the combination XY. For determination of the CMC of SLS in water, the final SLS concentration in water was prepared in a similar fashion as described above, but the Kruss instrument was used instead, to measure the surface tension as a function of SLS concentration. The surface tension measurements were collected in triplicate per sample and the average value was used to determine the CMC of SLS in water. 
Table 1. Dilution scheme for the preparation of the different media with different SLS concentration.

\begin{tabular}{cccc}
$\begin{array}{c}\text { Volume of 20 mM SLS Bulk } \\
\text { Solution of Media }(\mathrm{mL})\end{array}$ & Volume of Media $(\mathrm{mL})$ & Total Volume $(\mathrm{mL})$ & Final SLS concentration $(\mathrm{mM})$ \\
\hline 0.1 & 19.9 & 20.0 & 0.1 \\
0.2 & 19.8 & 20.0 & 0.2 \\
0.4 & 19.6 & 20.0 & 0.4 \\
0.6 & 19.4 & 20.0 & 0.6 \\
0.8 & 19.2 & 20.0 & 0.8 \\
1.0 & 19.0 & 20.0 & 1.0 \\
1.5 & 18.5 & 20.0 & 1.5 \\
2.0 & 18.0 & 20.0 & 2.0 \\
4.0 & 16.0 & 20.0 & 4.0 \\
6.0 & 14.0 & 20.0 & 6.0 \\
8.0 & 12.0 & 20.0 & 8.0 \\
10.0 & 10.0 & 20.0 & 10.0 \\
12.0 & 8.0 & 20.0 & 12.0 \\
14.0 & 6.0 & 20.0 & 14.0 \\
16.0 & 4.0 & 20.0 & 16.0 \\
18.0 & 2.0 & 20.0 & 18.0 \\
20.0 & 0.0 & 20.0 & 20.0
\end{tabular}

\section{STATISTICAL ANALYSIS}

\section{STUDENT T-TEST}

A comparison of the individual means or average absorbance (Figure $3 \mathrm{~A}, \mathrm{~B}$, and C) for Compound $\mathrm{X}$ and Compound $\mathrm{Y}$ was carried out using the independent student t-test to compute the probability values or $p$-values to determine if there is a significant difference between the two means. For this comparison, graphs that are closest to each other in the same figure were compared. That is, the individual average absorbance values were compared with each other at specific SLS concentration. For example, in Figure 3A the average absorbance values for 'Compound $X$ ' in water and 'Compound $\mathrm{X}$ in water \& Compound $\mathrm{Y}$ ' were statistically compared at each SLS concentration using the independent student t-test. An independent t-test was used to compare the averages of two samples because the two groups or samples are not the same. There are two types of independent t-tests: equal variance and unequal variance. An equal variance (pooled variance) independent t-test was used because the number of subjects in the two groups were the same as well as the variance of the two groups were considered similar. A confidence level or level of significance of $p<0.05$ was considered significant. The statistical analysis was carried out in Microsoft Excel 2016 for Windows.

\section{ANALYSIS OF VARIANCE (ANOVA)}

The statistical analysis of the solubility of Compound $\mathrm{X}$ and the solubility of Compound $\mathrm{Y}$ were conducted separately. For each drug, a general linear model was developed using JMP v14.2 software. There are two categorical factors (media type, presence of Compound X or Compound Y) and one continuous factor (SLS concentration). A full factorial model was used for this analysis. This includes the three main effects and all three twofactor interactions, plus a single three-factor interaction, and the intercept. This may be considered as an analysis of covariance (ANCOVA) because it is important to understand the changes in slope of solubility compared to SLS for the various media and drug combinations. The experiments were conducted in phases, which may be considered a block effect. However, the effect of phase and the presence of Compound $\mathrm{X}$ or Compound $\mathrm{Y}$ are 
confounded and there is no way to independently separate their effects. Additionally, the solubility of Compound $\mathrm{X}$ and Compound $\mathrm{Y}$ are independent when not in combination. For this analysis it is assumed that the solubility of Compound $\mathrm{X}$ and Compound Y are independent.

\section{DRUG-DRUG/DRUG-EXCIPIENT COMPATIBILITY}

The drug-drug/drug-excipient compatibility study tested binary blends of both drug substances (drugdrug) and each individual drug substance with SLS (drug-excipient) as surfactant. Additionally, control samples of each drug substance were set down.

Table 2 presents the composition of the active and binary blends. The drug substances, binary blends, and individual excipients were prepared and stored in clear scintillation vials loosely capped with polypropylene screw cap closures (without liner) at the following amounts:

- Drug substance (DS) controls of $125 \mathrm{mg}$ of model Compound $\mathrm{X}$ control and $100 \mathrm{mg}$ of model Compound Y control.

- $\quad$ 1:4 mixtures of Compound $X$ and Compound $Y$ (25 $\mathrm{mg}$ and $100 \mathrm{mg}$ respectively, accurately weighed).

- 1:0.5 or 1:0.1 mixture of each drug substance (125 mg Compound X and $100 \mathrm{mg}$ Compound $\mathrm{Y}$, accurately weighed) and each excipient in ratios depending on the function of the excipient as well as the amount used in the Adcirca formulation.

- Approximately $100 \mathrm{mg}$ of SLS stored alone (excipient control).

The drug substances, and binary blends were set down at storage conditions of $40^{\circ} \mathrm{C} / 75 \% \mathrm{RH}$ and $50^{\circ} \mathrm{C} /$ ambient $\mathrm{RH}$. The samples were removed from each storage condition, and chemically and physically analyzed to ensure stability at the following time points $\mathrm{t}=0,2$, and 4 weeks as per Table 3.

\section{PERMEABILITY}

Caco-2 monolayers were grown to confluence on collagen-coated, microporous, polycarbonate membranes in 12-well Costar Transwell plates. The permeability assay buffer was Hanks Balanced Salt solution containing $10 \quad \mathrm{mM} \quad 4-(2-$ Hydroxyethyl)piperazine-1-ethanesulfonic acid (HEPES) and $15 \mathrm{mM}$ glucose, at $\mathrm{pH}$ 7.4. In some experiments, the assay buffer also contained $10 \mu \mathrm{M}$ Cyclosporin A (P-gp inhibitor). The test article dosing concentration was $10 \mu \mathrm{M}$ in the assay buffer. All cell monolayers were preincubated for 30 minutes with the appropriate assay buffer. Cells were dosed on the apical side (A to B) or basolateral side (B to A) and incubated at $37^{\circ} \mathrm{C}$ with $5 \%$ carbondioxide in a humidified chamber. After 2 hours, a $200 \mu \mathrm{L}$ aliquot was taken from the receiver and donor chambers. Each determination was performed in duplicate. All samples were assayed by LC/MS using electrospray ionization. The transport rate for a particular concentration of a test compound is typically expressed as the apparent permeability coefficient (Papp), which is calculated using the following equation:

$$
P_{a p p}=\frac{V_{r} \times \frac{d C_{r}}{d t}}{A \times C_{o}}
$$

where $V_{r}$ is the volume of the receiver compartment in $\mathrm{cm}^{3}, \frac{d C_{r}}{d t}$ is the slope of the cumulative concentration of the compound in the receiver compartment over time in $\mu M s^{-1}, \mathrm{~A}$ is the surface area of cell monolayer in $\mathrm{cm}^{2}$, and $C_{0}$ is the compound initial concentration in the donor compartment (25).

Table 2. Drug-Excipient Compatibility Binary Mixtures.

\begin{tabular}{cccc}
\hline \multicolumn{1}{c}{ Binary mixtures } & & Ratio of DS:Excipient & Comments \\
\hline Model Compound X & N/A & $1: 0$ & Control \\
\hline Model Compound Y & N/A & $1: 0$ & Control \\
\hline SLS & N/A & $0: 1$ & Control \\
\hline Compound X & Compound Y & $1: 4$ & DS-DS \\
\hline Compound X & SLS & $1: 0.5$ & $\begin{array}{c}\text { Based on critical micelle } \\
\text { concentration (CMC) }\end{array}$ \\
Compound Y & SLS & $1: 0.1$ & $\begin{array}{c}\text { Based on critical micelle } \\
\text { concentration (CMC) }\end{array}$ \\
\hline
\end{tabular}


Table 3. Storage Conditions and Test Time Points for Binary Mixtures and Controls.

\begin{tabular}{|c|c|c|c|c|}
\hline \multirow{2}{*}{ Samples } & \multirow{2}{*}{ Storage Conditions } & \multicolumn{3}{|c|}{ Time Points, Weeks } \\
\hline & & $\mathbf{0}$ & 2 & 4 \\
\hline \multirow{4}{*}{ Drug substance control } & $50^{\circ} \mathrm{C} / \mathrm{Amb} \% \mathrm{RH}$, Open & \multirow{4}{*}{ A } & \multirow{2}{*}{ A } & \multirow{2}{*}{ A } \\
\hline & $40^{\circ} \mathrm{C} / 75 \% \mathrm{RH}$, Open & & & \\
\hline & $50^{\circ} \mathrm{C} / \mathrm{Amb} \% \mathrm{RH}$, Closed & & \multirow[b]{2}{*}{$\mathrm{B}$} & \multirow[b]{2}{*}{$\mathrm{B}$} \\
\hline & $40^{\circ} \mathrm{C} / 75 \% \mathrm{RH}$, Closed & & & \\
\hline \multirow{4}{*}{$\begin{array}{c}\text { Compound } \mathrm{X} \& \text { Compound } \\
\mathrm{Y} \text { binary mixture }\end{array}$} & $50^{\circ} \mathrm{C} / \mathrm{Amb} \% \mathrm{RH}$, Open & \multirow{4}{*}{ A } & \multirow{2}{*}{ A } & \multirow{2}{*}{ A } \\
\hline & $40^{\circ} \mathrm{C} / 75 \% \mathrm{RH}$, Open & & & \\
\hline & $50^{\circ} \mathrm{C} / \mathrm{Amb} \% \mathrm{RH}$, Closed & & & \\
\hline & $40^{\circ} \mathrm{C} / 75 \% \mathrm{RH}$, Closed & & B & B \\
\hline \multirow{4}{*}{ Drug substance and SLS } & $50^{\circ} \mathrm{C} / \mathrm{Amb} \% \mathrm{RH}, \mathrm{Open}$ & \multirow{4}{*}{ A } & \multirow{2}{*}{ A } & \multirow{2}{*}{ A } \\
\hline & $40^{\circ} \mathrm{C} / 75 \% \mathrm{RH}$, Open & & & \\
\hline & $50^{\circ} \mathrm{C} / \mathrm{Amb} \% \mathrm{RH}$, Closed & & \multirow[b]{2}{*}{$\mathrm{B}$} & \multirow[b]{2}{*}{$\mathrm{B}$} \\
\hline & $40^{\circ} \mathrm{C} / 75 \% \mathrm{RH}$, Closed & & & \\
\hline \multirow{4}{*}{ SLS alone } & $50^{\circ} \mathrm{C} / \mathrm{Amb} \% \mathrm{RH}, \mathrm{Open}$ & \multirow{2}{*}{ A } & \multirow{2}{*}{ A } & \multirow{2}{*}{ A } \\
\hline & $40^{\circ} \mathrm{C} / 75 \% \mathrm{RH}$, Open & & & \\
\hline & $50^{\circ} \mathrm{C} / \mathrm{Amb} \% \mathrm{RH}$, Closed & \multirow{2}{*}{$\mathrm{O}$} & \multirow{2}{*}{$\mathrm{B}$} & \multirow{2}{*}{ B } \\
\hline & $40^{\circ} \mathrm{C} / 75 \% \mathrm{RH}$, Closed & & & \\
\hline
\end{tabular}

Note: For Compound $\mathrm{X}$ and Compound Y drug substance binary mixtures, 2 vials were pulled and tested for each time point and conditions. $\mathrm{A}=$ Conduct testing; $\mathrm{B}=$ Testing to be carried out if results from the open vials showed more than $10 \%$ potency loss or increase in related substances greater than $0.5 \%$; $\mathrm{O}=$ Optional testing. The samples were tested for appearance, drug content and related substances (degradants) by HPLC.

\section{MECHANISTIC ABSORPTION MODEL}

All software models were built using gCOAS (A gPROMS language based Computational Oral Absorption Simulation Framework). The mechanistic model $(26,27)$ incorporates the physicochemical and formulation characterization information to simulate the dissolution of an orally administered tablet in the gastrointestinal (GI) tract and subsequent absorption of the drugs from the GI tract, while considering the physiology $(28,29)$. The modeling was performed to understand the impact of drug solubility on in-vivo dissolution and absorption. The effects of surfactant-enhanced solubilities on drug dissolution and absorption were also modeled. The mechanistic absorption model was developed considering the drug's physicochemical properties (dose X1 and $\mathrm{Y} 1$ for Compound $\mathrm{X}$ and $\mathrm{Y}$ respectively, solubility, molecular weight, particle size), permeability and physiology $(\mathrm{pH}$, transit time, volume, length, bile salts).

\section{RESULTS}

\section{CRITICAL MICELLE CONCENTRATIONS}

Surfactants are water-soluble amphiphilic molecules that consist of a non-polar hydrophobic tail and a polar hydrophilic head group. SLS is an anionic surfactant. The hydrophobic tail and hydrophilic head group allows the surfactant to have a high affinity to adsorb at interfaces and association in solution to form micelles. The concentration at which surfactants start to form micelles is called critical micelle concentration (CMC). Several techniques have been reported to determine the CMC including surface tension, conductivity, fluorescence, and UV-Visible spectrophotometry $(30,31)$. Two of these techniques have been applied in this work; surface tension using the Kruss K100 instrument and UV-Visible absorption. The surface tension measurements were used only to confirm that the SLS stock solution that was used in all the experiments has a CMC in water. Due to the timeconsuming nature of the surface tension experiments and the large number of samples that needed to be run ( $\sim 50$ samples), the higher throughput, automated UV-Visible spectrophotometer technique was employed.

In Figure 1, experimental data of the surface tension measurement as a function of SLS concentration in water is presented. The surface tension decreases when the surfactant concentration in the aqueous solution increases. This effect is due 
to the adsorption of surfactant molecules at the interface. The drop of surface tension stops when the surfactant starts to form micelles in solution at the CMC. The surface tension remains virtually constant at surfactant concentrations above the CMC. Therefore, the CMC of SLS at $25^{\circ} \mathrm{C}$ determined from the graph is $\sim 8 \mathrm{mM}$. This measurement is in line with the CMC value reported in the literature of approximately $8.2 \mathrm{mM}(31)$.

\section{ABSORBANCE MEASUREMENTS}

As previously mentioned in the HPLC method section, the absorbance wavelengths for Compound $\mathrm{X}$ and Compound $\mathrm{Y}$ were $262 \mathrm{~nm}$ and $285 \mathrm{~nm}$ respectively. These wavelengths were used to track the absorbance profiles of the samples containing Compound $\mathrm{X}$ and Compound $\mathrm{Y}$ using the UVVisible spectrophotometry technique. Example UVVis absorbance spectra for Compound X (Panel A) and Compound $\mathrm{Y}$ (Panel B) in various concentrations of SLS in water is shown in Figure 2. As the concentration of SLS in water increases, the absorbance at the particular wavelength also increases, demonstrating that the amount of drug in solution increases with increased SLS concentration. Each sample was tested in triplicate and the average absorbances at the target wavelengths were plotted against the SLS concentrations. The inflection point (intersection of linear fits) in the graphs of absorbance versus SLS concentration was used to obtain the CMC of SLS in each media, as described in following sections. The CMC of SLS in the presence of model compounds $\mathrm{X}$ and $\mathrm{Y}$ were determined in various media including water, SGF, and FeSSIF. An attempt was made to determine the CMC of SLS in the presence of model compounds X and $\mathrm{Y}$ in fasted state simulated intestinal fluid (FaSSIF), however SLS was not soluble in FaSSIF and the experiments were not progressed any further. Figure 3 presents the experimentally determined effects of SLS concentration on the UV absorbance of model compounds $\mathrm{X}$ and $\mathrm{Y}$ in water, SGF and FeSSIF, respectively.

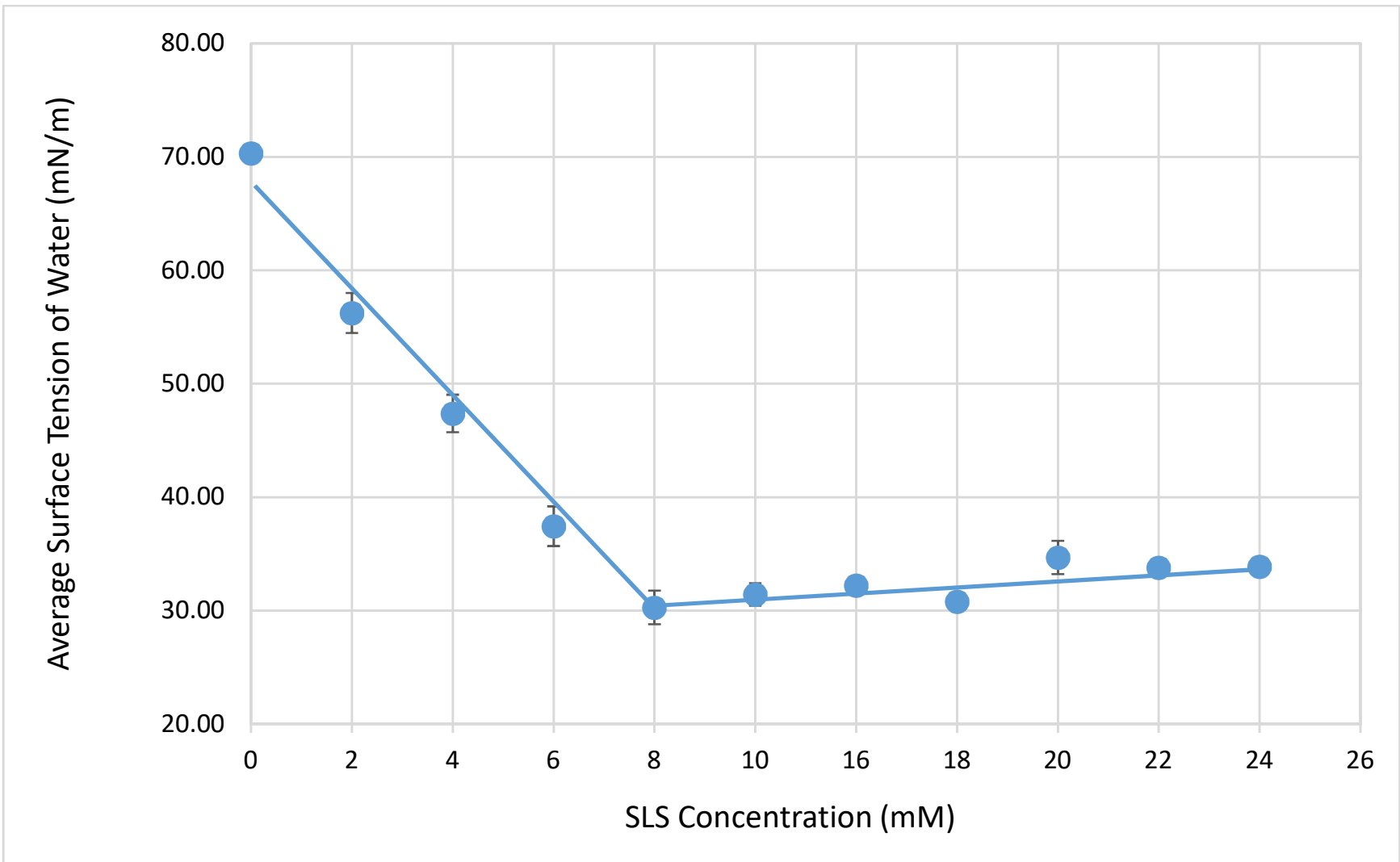

Figure 1. Surface tension measurements of SLS in water at $25^{\circ} \mathrm{C}$. The error bars are the standard deviations. 

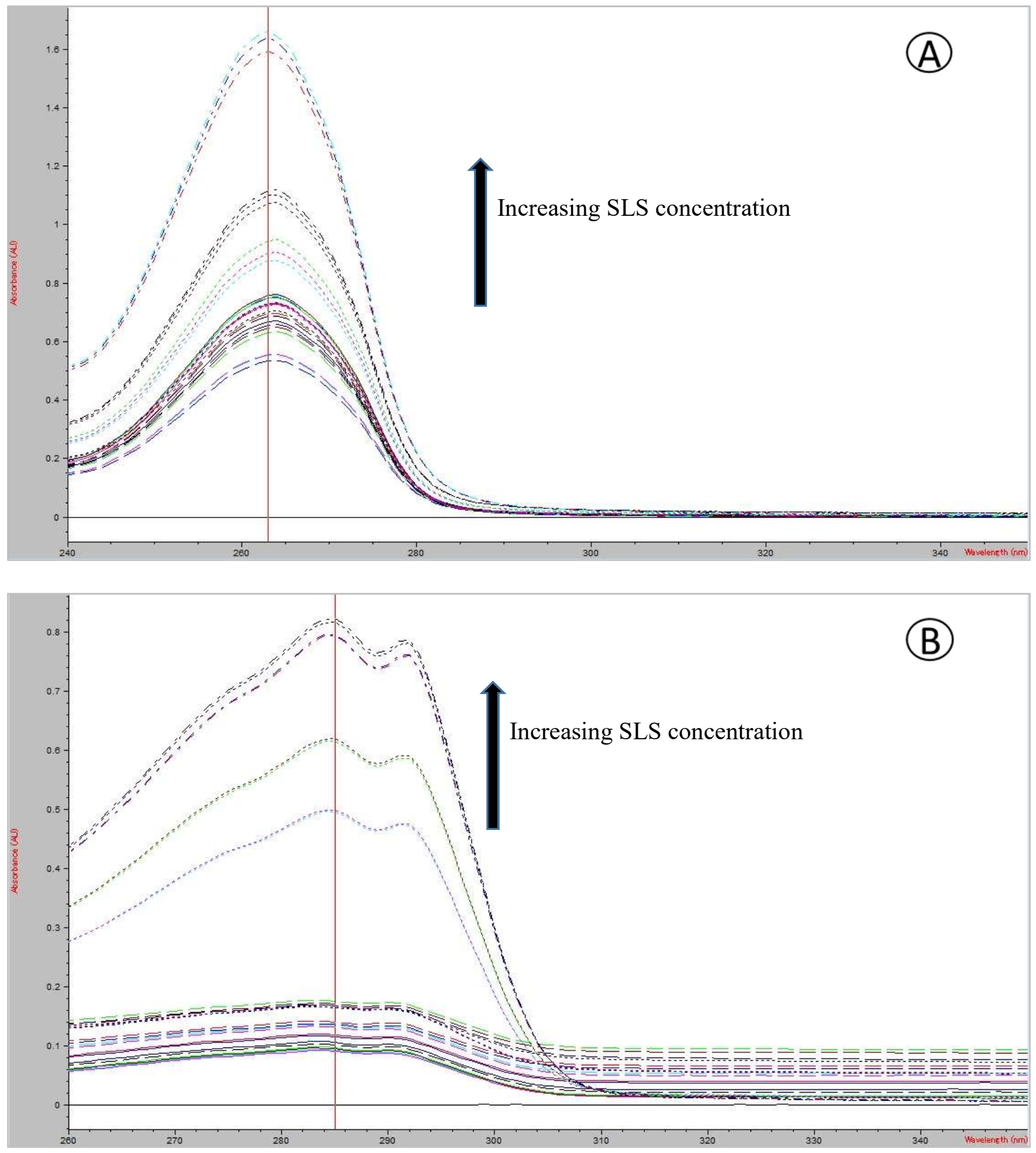

Figure 2. Absorbance spectra of Compound $\mathrm{X}$ and Compound $\mathrm{Y}$ in different concentrations of SLS in water, determined through UV-Vis experiments. Panel A, absorbance versus wavelength spectra for Compound X in increasing concentrations of SLS. Panel B, absorbance versus wavelength spectra for Compound Y in increasing concentrations of SLS. 
J Pharm Pharm Sci (www.cspsCanada.org) 22, 221 - 246, 2019
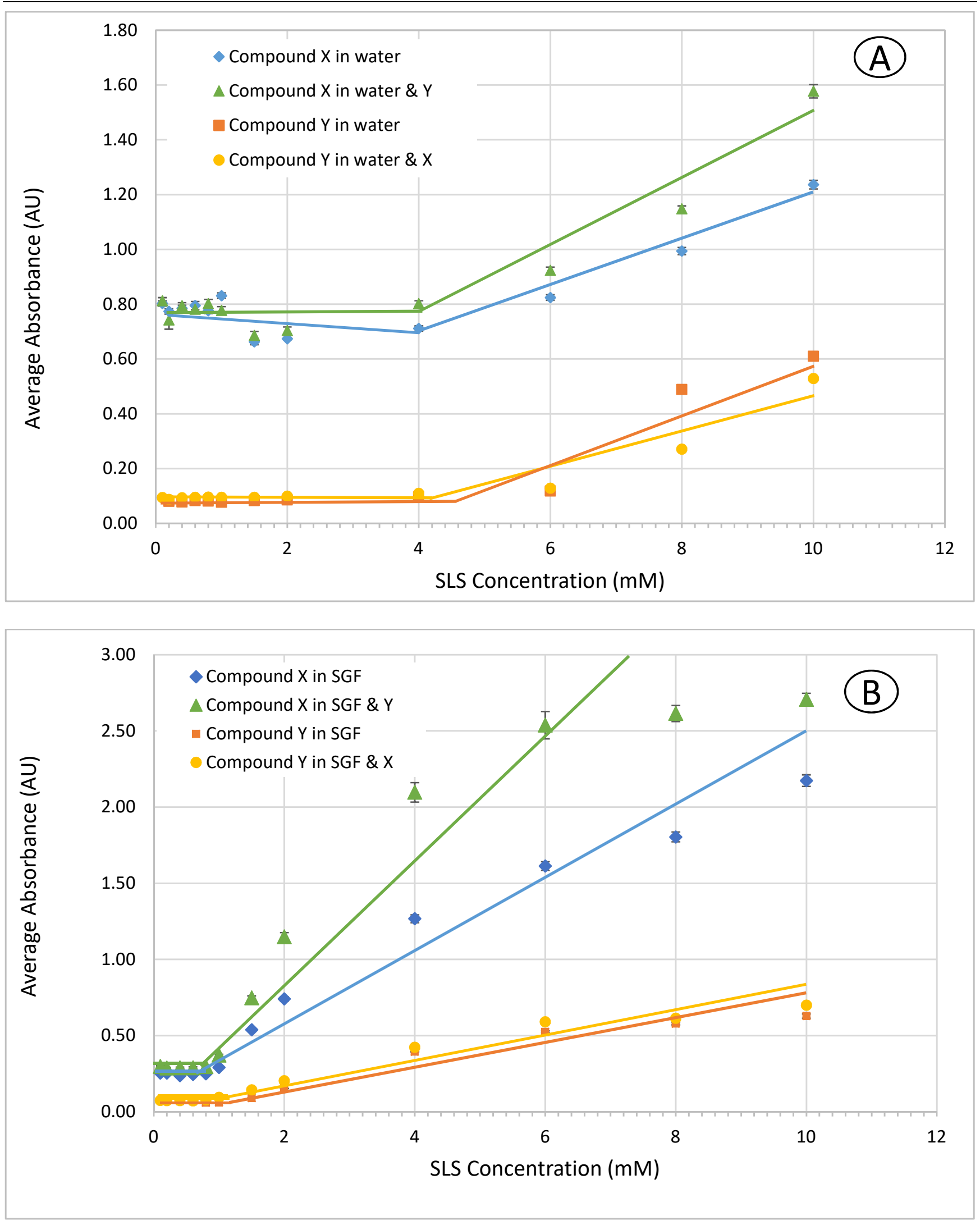


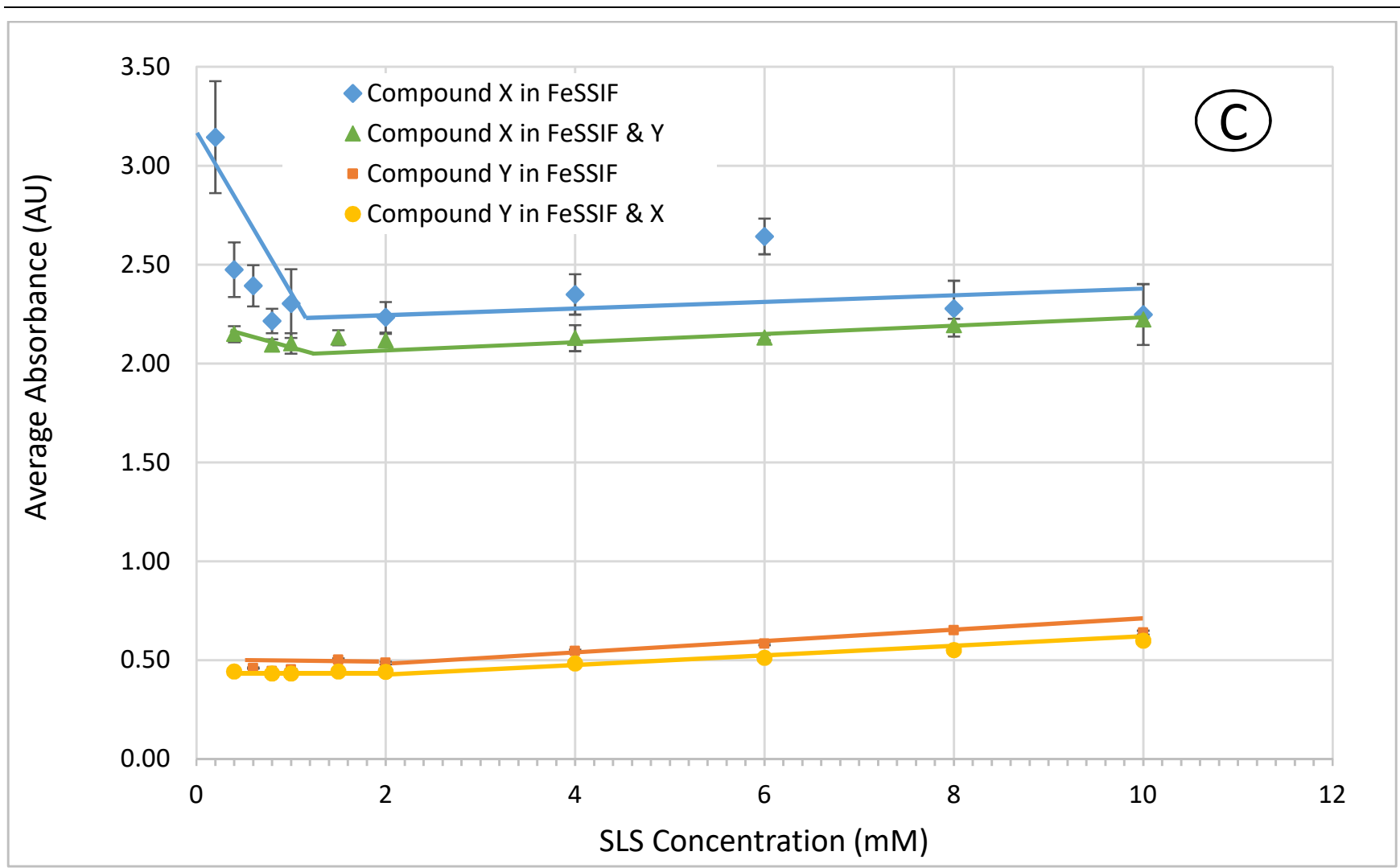

Figure 3. The effect of SLS concentration on the UV absorption of model Compounds $\mathrm{X}$ and $\mathrm{Y}$ in (Panel A, two-way t-test $\mathrm{p}<0.05$ ) water at $25^{\circ} \mathrm{C}$, (Panel B, two-way t-test $\mathrm{p}<0.05$ ) SGF $\mathrm{pH} 1.6$ at $25^{\circ} \mathrm{C}$ and (Panel C, two-way t-test $\mathrm{p}<0.05$ above $\mathrm{CMC}$ value) FeSSIF pH 6.5 at $25^{\circ} \mathrm{C}$. The adsorption wavelengths for Compounds $\mathrm{X}$ and $\mathrm{Y}$ were $262 \mathrm{~nm}$ and $285 \mathrm{~nm}$, respectively. The results are shown as mean \pm standard deviation of mean $(n=3)$.

As SLS concentration increased, there is an inflection point where the UV absorbance of compounds $\mathrm{X}$ and $\mathrm{Y}$ rapidly increases, this inflection point indicates the CMC of SLS in the system. The CMC of SLS in each of the media evaluated in this study was determined to be similar as individual compounds and in combination. The CMC values were estimated through a determination of the inflection points on each of the graphs in Figure 3, and are presented in Table 4.

The CMC of SLS in presence of Compounds X and $\mathrm{Y}$ was determined to decrease generally in the following order: water $>$ FeSSIF $>$ SGF.

Table 4. CMC values of SLS in various media containing model Compounds $\mathrm{X}$ and $\mathrm{Y}$.

\begin{tabular}{lcccc}
\hline \multirow{r}{r}{ Media } & Compound $\mathbf{X}$ & Compound $\mathbf{Y}$ & Compound $\mathbf{X}$ in XY & Compound $\mathbf{Y}$ in XY \\
\hline Water & 4.0 & 4.6 & 4.0 & 4.2 \\
FeSSIF & 1.2 & 2.0 & 1.3 & 2.0 \\
SGF & 0.8 & 1.2 & 0.8 & 1.0 \\
\hline
\end{tabular}




\section{THERMODYNAMICS OF MICELLIZATION}

To understand the aggregation of SLS in the biorelevant media in the presence of Compound $\mathrm{X}$ and Compound $\mathrm{Y}$, the standard free energy of micellization $\left(\Delta G_{m}^{0}\right)$ was calculated. This thermodynamic parameter was expressed and previously used by Bhardwaj et al.(30). The equation for calculating the standard Gibbs free energy of micellization is presented below:

$$
\Delta G_{m}^{0}=R T \ln (\mathrm{cmc})
$$

where $\mathrm{R}$ and $\mathrm{T}$ represents the universal gas constant in Joule per mole per Kelvin (8.31 $\mathrm{Jmol}^{-1} \mathrm{~K}^{-1}$ ) and temperature in Kelvin $(298.2 \mathrm{~K})$, respectively. The CMC of SLS is expressed in moles per liter.

The Gibbs free energy of SLS micelle formation in the media investigated containing compounds $\mathrm{X}$ and $\mathrm{Y}$ are presented in Table 5. The negative values of the Gibbs free energy of micellization indicated that the process is spontaneous. Also, the aggregation of SLS in the various media is overall more spontaneous in the following order: $\mathrm{SGF}>\mathrm{FeSSIF}>$ water.

\section{DRUG-DRUG/DRUG-EXCIPIENT COMPATIBILITY}

SLS is included in the oral dosage formulation as a wetting agent/surfactant. The intent is that when the drug substance and SLS combination are in an aqueous media, intimate contact of the SLS can occur with the drug particles to either lower the surface tension of the drug substance, or increase its solubility through micelle formation in the gastrointestinal contents to enhance dissolution (32).

Physical stability was assessed on the samples stored up to 4 weeks by monitoring the appearance inside the vials. There was no change in the physical appearance of the content inside the vials stored under the various conditions. The appearance test indicated that the individual and binary blends were physically stable.

The chemical stability of the drug substances and binary blends stored at the various conditions in open glass vials for up to 4 weeks showed no compatibility issues in purity and content. All content assay values were within $90-110 \%$. There was no impurity level observed greater than $0.2 \%$ area of the main peak in the study samples. Evaluation of the drug substance controls and the binary blend of drug substances resulted in the following observations;
- At $\mathrm{T}=4$ weeks a peak at relative retention time (RRT) 0.54 was reported at $0.13 \%$ area in the Compound $\mathrm{X}$ control sample stored at $50^{\circ} \mathrm{C} / \mathrm{Amb} \mathrm{RH}$ in open vial.

- $\quad$ At T=4 weeks an impurity peak at RRT 0.81 was reported at $0.06 \%$ area in the Compound $\mathrm{Y}$ control sample stored in open vial at $50^{\circ} \mathrm{C} / \mathrm{Amb}$ $\mathrm{RH}$.

- Additionally, impurity peaks at RRT 0.91 and 1.28 were reported at levels of $0.07 \%$ area in the Compound X-Compound Y binary blend stored in open vials at $40^{\circ} \mathrm{C} / 75 \% \mathrm{RH}$ for $\mathrm{T}=4$ weeks.

The data indicated that SLS was compatible with both Compound X and Compound Y. Since the impurity levels reported at accelerated and stress conditions in the binary blend of drug substances and the drug substance controls were low, it was concluded that there are no compatibility issues between Compound $\mathrm{X}$ and Compound $\mathrm{Y}$ drug substances, and between the drug substances and SLS binary mixtures.

\section{HIGH THROUGHPUT EXPERIMENTATION OF COMPOUND X AND COMPOUND Y WITH SODIUM LAURYL SULFATE IN BIORELEVANT MEDIA}

As mentioned above, high throughput experimentation was carried out using the Unchained Labs Freeslate automation platform, where up to 96 samples could be prepared and analyzed in a rapid and sequential manner, as described by Zheng et al (33). Each sample was prepared and analyzed in triplicate and the average of the data set was used for comparison and interpretation. When automated experiments in biorelevant media are designed, one hour and eight hours are commonly selected to indicate solubility in the upper GI tract. For the data presented here, a comparison of the one hour and eight hour data revealed that there was no significant change in concentration of either drug, so the figures in the following section represent one hour data. The overall average relative standard deviation between the one hour and eight hour data was calculated to be $11.4 \%$, which provides a high level of confidence that the measured concentrations were at the equilibrium solubility in the respective media at the one hour timepoint. 
Table 5. Standard Gibbs free energy of SLS micellization of Compounds $X$ and $Y$ in Water, FeSSIF and SGF .

\begin{tabular}{lcccc}
\hline \multirow{2}{*}{ Media } & \multicolumn{4}{c}{ SLS Standard free energy of micellization $\left(\Delta G_{m}^{0}\right), \mathbf{K J} / \mathbf{M o l}$} \\
& Compound $\mathbf{X}$ & Compound $\mathbf{Y}$ & Compound $\mathbf{X}$ in XY & Compound Y in XY \\
\hline Water & -13.68 & -13.34 & -13.68 & -13.56 \\
FeSSIF & -16.67 & -15.40 & -16.47 & -15.40 \\
SGF & -17.67 & -16.67 & -17.67 & -17.12 \\
\hline
\end{tabular}

\section{EFFECT OF SLS ON COMPOUND X SOLUBILITY IN VARIOUS MEDIA}

The impact of SLS on the solubility of Compound X is presented in Figure 4. The data indicates a generally increasing trend in solubility with increasing levels of SLS. Additionally, the data confirms the poor water-solubility and shows that there is no significant impact of food effect on the solubility of Compound X. Based on the solubility data of Compound X in SLS, the most suitable level of SLS from a formulation design perspective would be $4 \mathrm{mg}$, as the expectation would have been to design the drug product for complete dissolution of the drug substance in the acidic $\mathrm{pH}$ of the stomach to allow maximum drug absorption in the small intestine. It is worth noting that this recommendation is specific to drug product containing only Compound X.

\section{EFFECT OF SLS ON COMPOUND Y SOLUBILITY IN VARIOUS MEDIA}

The impact of SLS on the solubility of Compound Y is presented in Figure 5. The data shows a general increasing trend in solubility with increasing levels of SLS. Additionally, the data confirms the poor water-solubility of Compound $\mathrm{Y}$ and shows that there is an increasing solubility due to a food effect (FeSSIF). Based on the solubility data of Compound $\mathrm{Y}$ in SGF, the most suitable level of SLS from a formulation design perspective would be $4 \mathrm{mg}$, as the expectation would have been to design the drug product for complete dissolution of the drug substance in the stomach (acidic $\mathrm{pH}$ ) to allow maximum drug absorption in the small intestine.

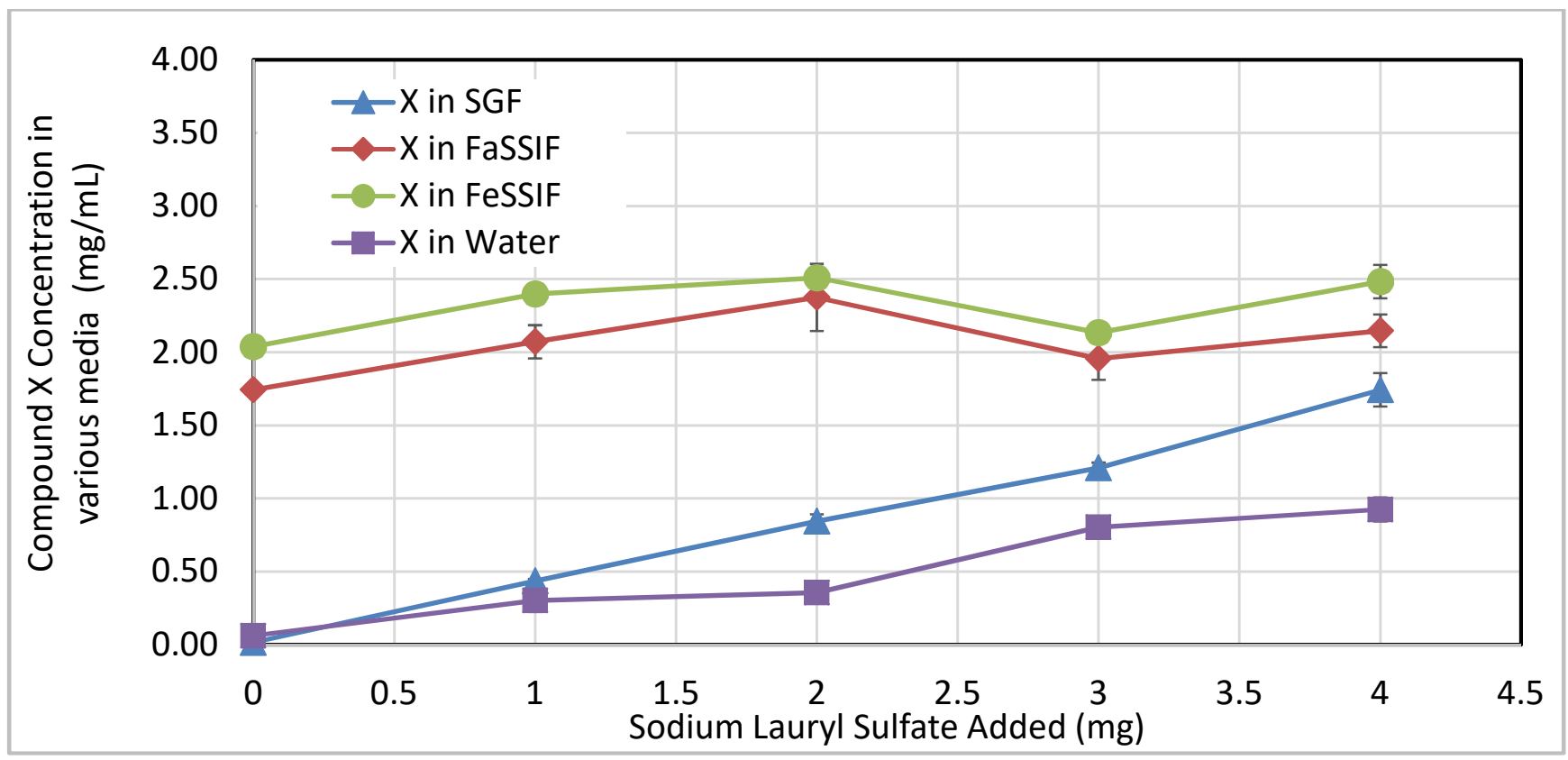

Figure 4. Effects of SLS on Compound X solubility in biorelevant media and water at 1 hour. The results are shown as mean \pm standard deviation of mean $(n=3)$. 


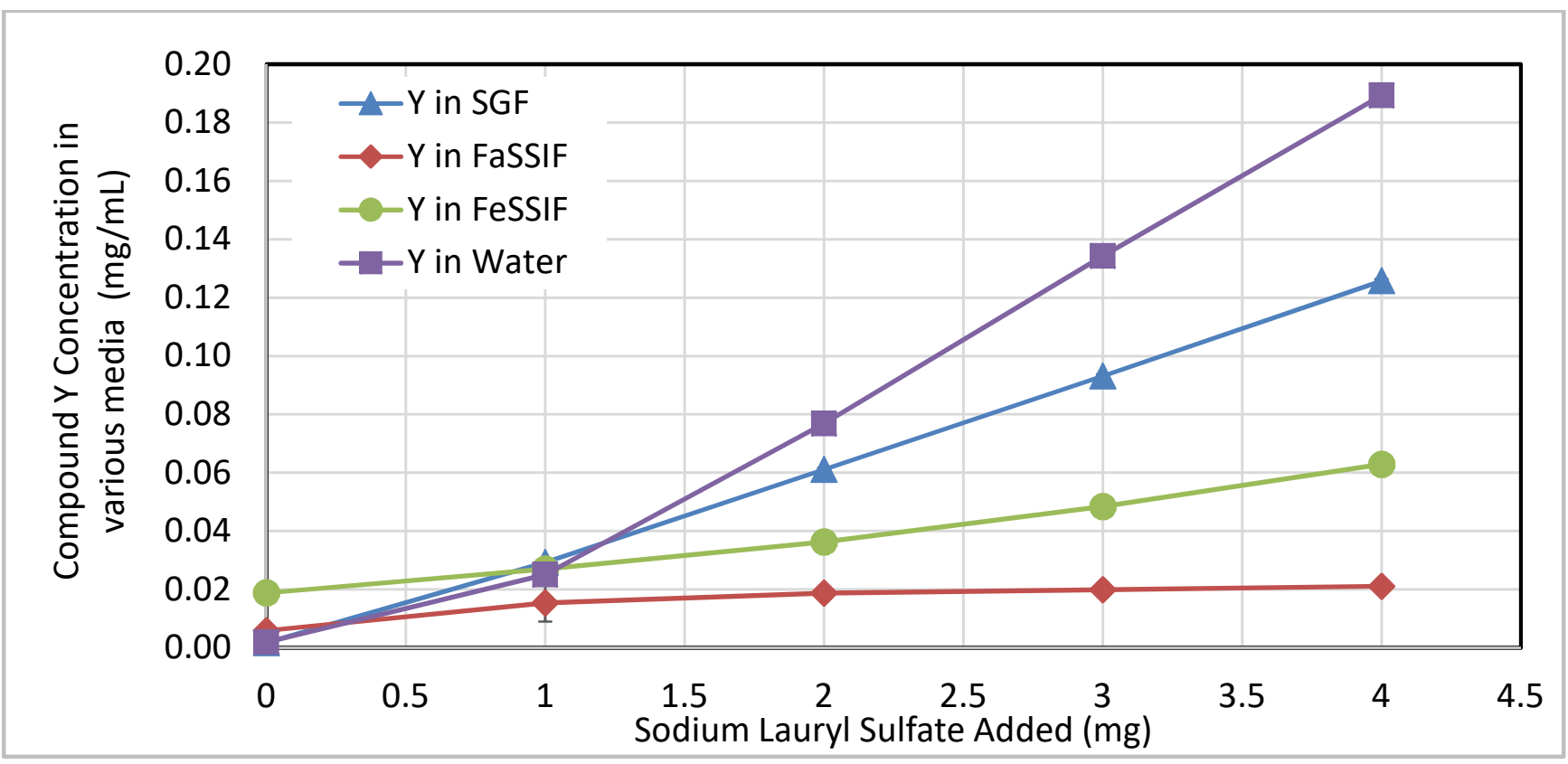

Figure 5. Effects of SLS on Compound Y solubility in biorelevant media and water at 1 hour. The results are shown as mean \pm standard deviation of mean $(n=3)$.

\section{IMPACT OF SLS ON COMPOUND X SOLUBILITY IN THE PRESENCE OF COMPOUND Y IN VARIOUS MEDIA}

The solubility profiles of Compound $\mathrm{X}$ in biorelevant media and different levels of SLS in the presence of a fixed amount of Compound $\mathrm{Y}$ is presented in Figure 6. The solubility of Compound $\mathrm{X}$ in the presence of Compound $\mathrm{Y}$ generally increases with increasing levels of SLS. However, the solubility of Compound X in FaSSIF and FeSSIF were similar as a function of SLS concentration. It was observed in SGF that the maximum solubility of Compound $\mathrm{X}$ in the presence of Compound $\mathrm{Y}$ was achieved with $2 \mathrm{mg}$ SLS, which is different compared to the solubility of Compound $\mathrm{X}$ alone in SGF where a gradual increase in Compound $\mathrm{X}$ solubility was observed as a function of SLS concentration. Therefore, in designing a fixed dose combination (FDC) oral solid product containing both Compound X and Compound Y, 2 mg of SLS would be preferred to ensure maximum dissolution of Compound $\mathrm{X}$ in the stomach and ultimately an increase in intestinal absorption.

\section{IMPACT OF SLS ON COMPOUND Y SOLUBILITY IN THE PRESENCE COMPOUND X IN VARIOUS MEDIA}

The solubility profiles of Compound $\mathrm{Y}$ in biorelevant media and different levels of SLS in the presence of a fixed amount of Compound $\mathrm{X}$ is presented in Figure 7. The solubility of Compound $\mathrm{Y}$ in the presence of Compound $\mathrm{X}$ generally increases with increasing levels of SLS. However, the solubility of Compound $\mathrm{Y}$ in FaSSIF and FeSSIF were similar as a function of SLS concentration. In SGF, the maximum solubility of Compound $Y$ in the presence of Compound $\mathrm{X}$ was achieved with $2 \mathrm{mg}$ SLS, which is different compared to the solubility of Compound $\mathrm{Y}$ alone in SGF where a gradual increase in Compound $\mathrm{Y}$ solubility was observed as a function of SLS concentration. Therefore, in designing a fixed dose combination (FDC) oral solid product containing both Compound $\mathrm{X}$ and Compound Y, $2 \mathrm{mg}$ of SLS would be preferred to ensure maximum dissolution of Compound $\mathrm{Y}$ in the stomach and ultimately an increase in intestinal absorption. 


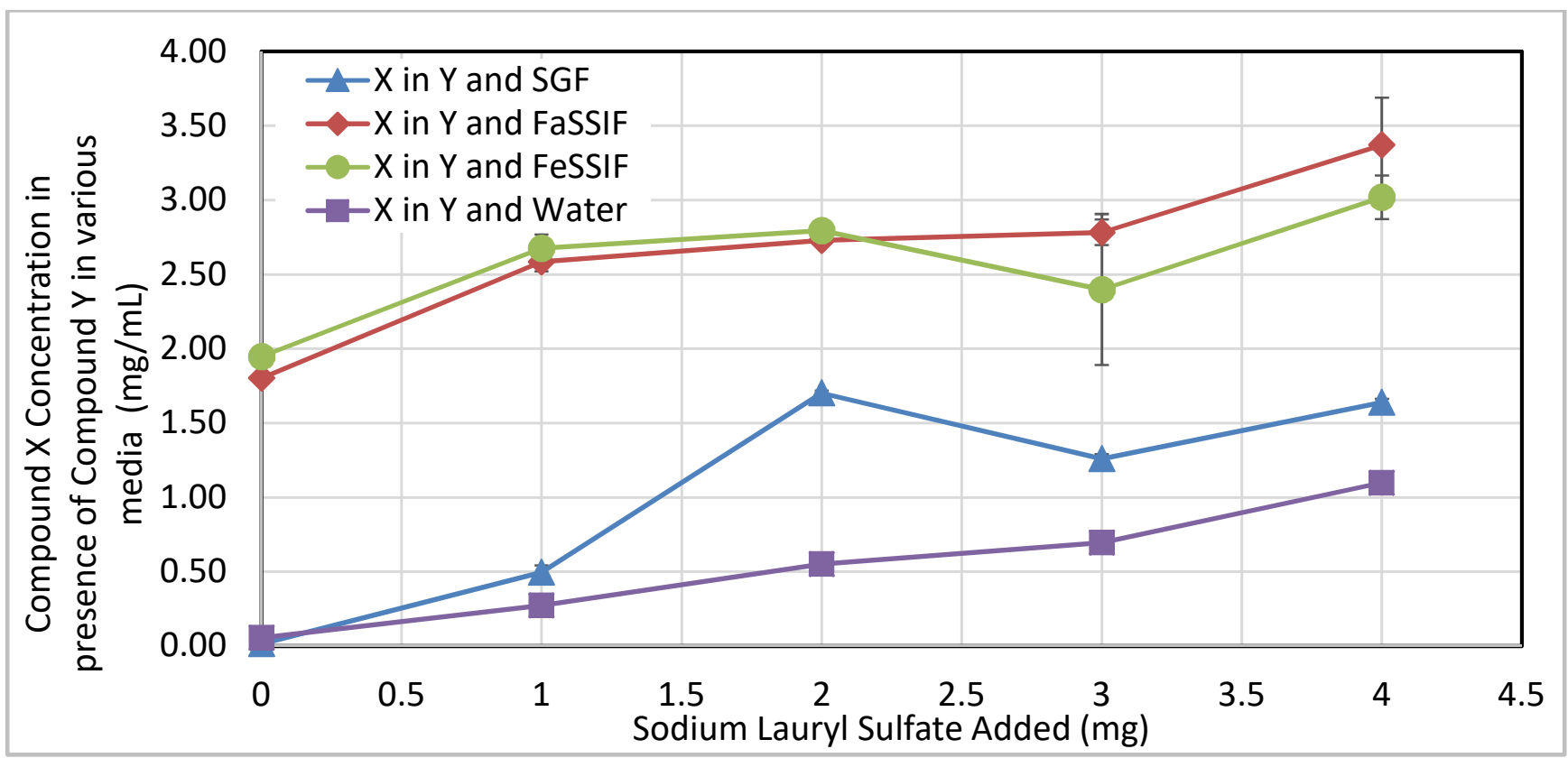

Figure 6. Solubility of Compound $\mathrm{X}$ in the presence of Compound $\mathrm{Y}$ in biorelevant media and water with different levels of SLS at 1 hour. The results are shown as mean \pm standard deviation of mean $(n=3)$.

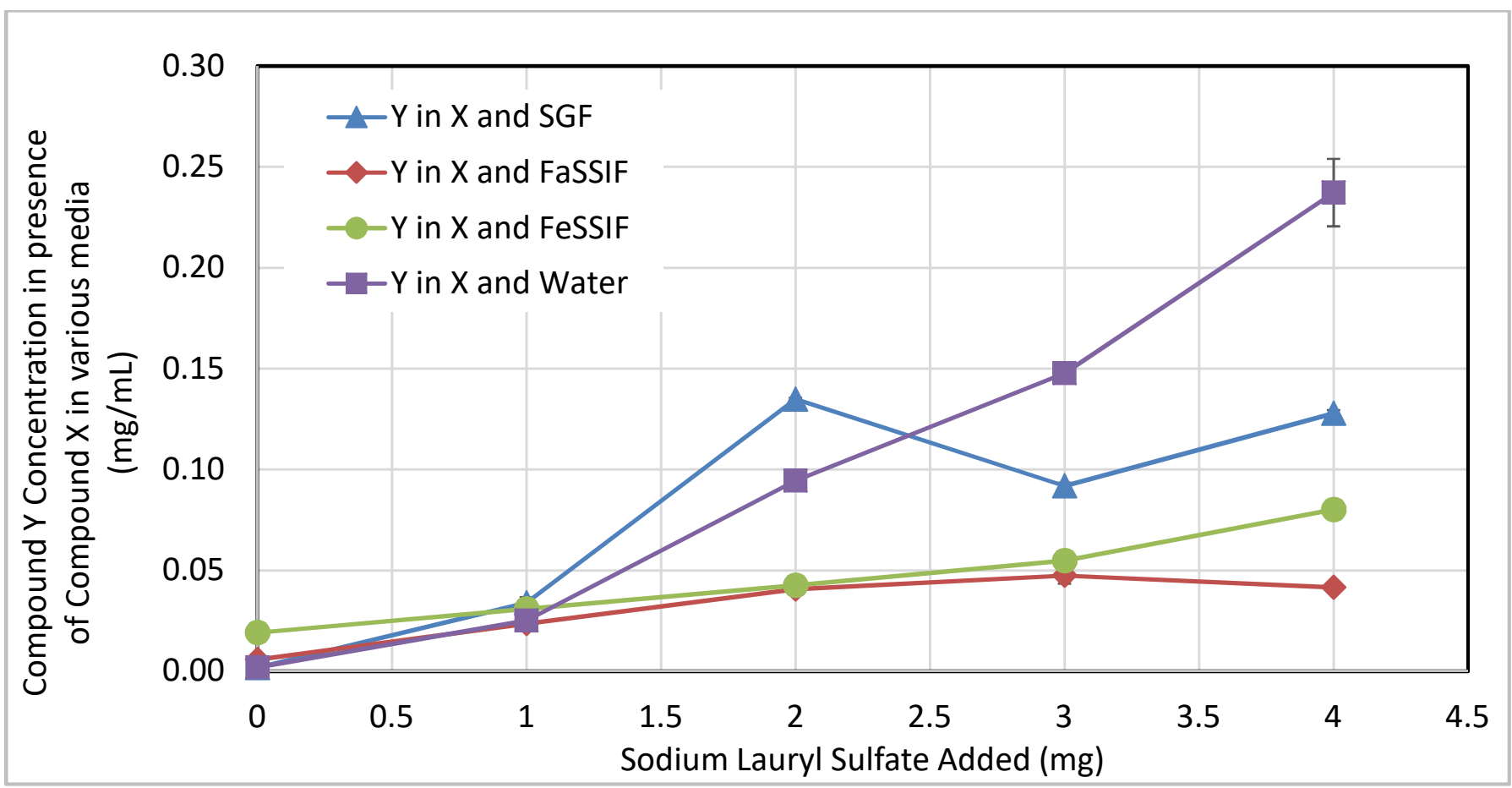

Figure 7. Solubility of Compound $\mathrm{Y}$ in the presence of Compound $\mathrm{X}$ in biorelevant media and water with different levels of SLS at 1 hour. The results are shown as mean \pm standard deviation of mean $(n=3)$. 


\section{STATISTICAL ANALYSIS}

\section{STUDENT T-TEST ANALYSIS OF ABSORBANCE RESULTS}

The results of $p$-values comparing the average absorbance values of both Compound $\mathrm{X}$ and Compound $\mathrm{Y}$ in the different media as shown in Figure 3 are presented in Table 6 . The p-value results indicated that it is unlikely that the obtained difference between the average absorbance for the samples of both Compound $\mathrm{X}$ and Compound $\mathrm{Y}$ in the different media occurred by chance and the difference in the average absorbance probably exists in the populations from which it was drawn. It is noteworthy that in some of the graphs where the initial average absorbance is extremely close to each other, the p-values were found to be larger than the level of significance where the differences between the average absorbances were not significant. For example, the average absorbance of Compound $\mathrm{Y}$ in FeSSIF Compared with Compound Y in FeSSIF \& Compound $\mathrm{X}$ have $\mathrm{p}$-values $>0.05$ for the four initial data points suggesting that the average absorbance results for the two samples at SLS concentrations of $0.4,0.6,0.8$ and $1.0 \mathrm{mM}$ were not significantly different. Also, these insignificant differences between absorbance results were observed before the $\mathrm{CMC}$ values. In all figures, above the CMC the average absorbance values were significantly different in the comparison $\mathrm{p}<0.05$.

Table 6. Probability values ( $\mathrm{p}$-values) for absorbance data calculated using the student t-test to compare the difference between the mean absorbance values for Compound $\mathrm{X}$ and Compound $\mathrm{Y}$ in various media, assuming equal variances and level of significance 0.05 .

\begin{tabular}{ccccccc}
\hline \multirow{2}{*}{$\begin{array}{c}\text { SLS } \\
\begin{array}{c}\text { Concentration } \\
(\mathbf{m M})\end{array}\end{array}$} & \begin{tabular}{c} 
Probability Values (p-values) from student t-test for Compound X and Compound Y \\
\cline { 2 - 7 } \\
in Water $\mathbf{X}$ in \\
Water \& Y
\end{tabular} & $\begin{array}{c}\text { Y in Water } \\
\text { vs. Y in } \\
\text { Water \& X }\end{array}$ & $\begin{array}{c}\text { X in SGF } \\
\text { vs. X in } \\
\text { SGF \& Y }\end{array}$ & $\begin{array}{c}\text { Y in SGF } \\
\text { vs. Y in } \\
\text { SGF \& X }\end{array}$ & $\begin{array}{c}\text { X in FeSSIF } \\
\text { vs. X in } \\
\text { FeSSIF \& Y }\end{array}$ & $\begin{array}{c}\text { Y in FeSSIF } \\
\text { vs. Y in } \\
\text { FeSSIF \& X }\end{array}$ \\
\hline 0.10 & $2.185 \mathrm{E}-02$ & -- & $1.244 \mathrm{E}-03$ & -- & - & - \\
0.20 & $2.205 \mathrm{E}-02$ & $2.346 \mathrm{E}-03$ & $1.512 \mathrm{E}-03$ & -- & -- & - \\
0.40 & $4.803 \mathrm{E}-02$ & $1.212 \mathrm{E}-03$ & $1.014 \mathrm{E}-03$ & $1.636 \mathrm{E}-03$ & $1.867 \mathrm{E}-03$ & $4.328 \mathrm{E}-01$ \\
0.60 & $1.941 \mathrm{E}-02$ & $5.653 \mathrm{E}-03$ & $2.057 \mathrm{E}-03$ & $1.310 \mathrm{E}-01$ & $2.270 \mathrm{E}-03$ & $5.202 \mathrm{E}-02$ \\
0.80 & $8.087 \mathrm{E}-03$ & $3.323 \mathrm{E}-04$ & $1.966 \mathrm{E}-03$ & $7.447 \mathrm{E}-04$ & $1.878 \mathrm{E}-03$ & $1.566 \mathrm{E}-01$ \\
1.00 & $1.084 \mathrm{E}-03$ & $9.350 \mathrm{E}-05$ & $7.149 \mathrm{E}-05$ & $8.330 \mathrm{E}-05$ & $2.406 \mathrm{E}-01$ & $5.822 \mathrm{E}-02$ \\
1.50 & $6.318 \mathrm{E}-03$ & $1.393 \mathrm{E}-04$ & $2.798 \mathrm{E}-05$ & $1.290 \mathrm{E}-04$ & $9.137 \mathrm{E}-08$ & $9.759 \mathrm{E}-03$ \\
2.00 & $8.952 \mathrm{E}-04$ & $3.658 \mathrm{E}-04$ & $9.977 \mathrm{E}-05$ & $1.125 \mathrm{E}-04$ & $7.715 \mathrm{E}-03$ & $8.244 \mathrm{E}-03$ \\
4.00 & $1.564 \mathrm{E}-04$ & $2.356 \mathrm{E}-06$ & $2.470 \mathrm{E}-04$ & $1.471 \mathrm{E}-03$ & $1.822 \mathrm{E}-02$ & $1.180 \mathrm{E}-04$ \\
6.00 & $5.902 \mathrm{E}-04$ & $2.760 \mathrm{E}-05$ & $5.020 \mathrm{E}-04$ & $4.141 \mathrm{E}-03$ & $6.426 \mathrm{E}-03$ & $9.800 \mathrm{E}-03$ \\
8.00 & $1.292 \mathrm{E}-04$ & $6.754 \mathrm{E}-06$ & $7.263 \mathrm{E}-05$ & $2.310 \mathrm{E}-02$ & $3.554 \mathrm{E}-03$ & $5.823 \mathrm{E}-06$ \\
10.00 & $5.442 \mathrm{E}-06$ & $1.526 \mathrm{E}-04$ & $2.849 \mathrm{E}-03$ & $2.846 \mathrm{E}-02$ & $2.532 \mathrm{E}-05$ & $5.217 \mathrm{E}-02$ \\
\hline
\end{tabular}

\section{ANALYSIS OF VARIANCE (ANOVA) OF COMPOUNDS $X$ AND Y AS A FUNCTION OF MEDIA AND SLS CONCENTRATION}

The models provide a good fit to the data for both Compound $\mathrm{X}$ and Compound $\mathrm{Y}$ with an R-square value of 0.98 . There were at least 4 of 7 terms in the models that were statistically significant with pvalues $<<0.05$. Figure 8 shows the effect summary of Compound $\mathrm{X}$ and Compound $\mathrm{Y}$. For the solubility of Compound X (Panel A), media and SLS concentration have the largest effects. Media and SLS concentration are also involved in a significant interaction. The significant Media*SLS interaction indicates that the slope of Compound $\mathrm{X}$ solubility 
versus SLS concentration is different across the different media. Also, in the presence of Compound $\mathrm{Y}$ the slope of Compound $\mathrm{X}$ solubility is different when compared to the solubility of Compound $\mathrm{X}$ alone in the various media.

Panel B shows that SLS concentration and the SLS*Media interaction have the two largest effects on the solubility of Compound Y. Media, which is ranked third, is also significant. The significant Media*SLS interaction indicates that the slope of Compound Y solubility versus SLS concentration is different across the different media. Also, the solubility of Compound $\mathrm{Y}$ in the absence and presence of Compound $\mathrm{X}$ is different in the various media. This is similar to the behavior of Compound $\mathrm{X}$ described previously.

In Figure 9, the residual plots of both Compound $\mathrm{X}$ and Compound $\mathrm{Y}$ display good behavior and overall randomness, although there seems to be a slight increase in variability as the predicted values increase in magnitude. However, a transformation of the data does not make any appreciable improvements.

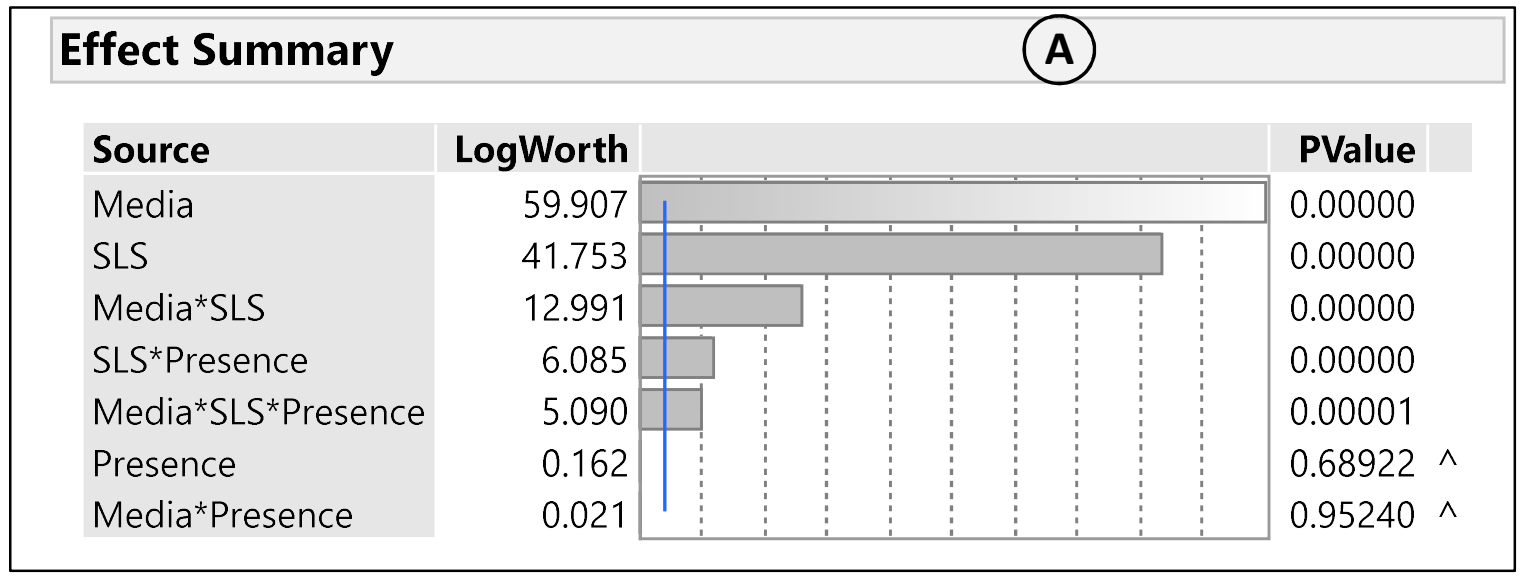

\section{Effect Summary}

(B)

Source
SLS
Media*SLS
Media
SLS*Presence
Media*SLS*Presence
Presence
Media*Presence

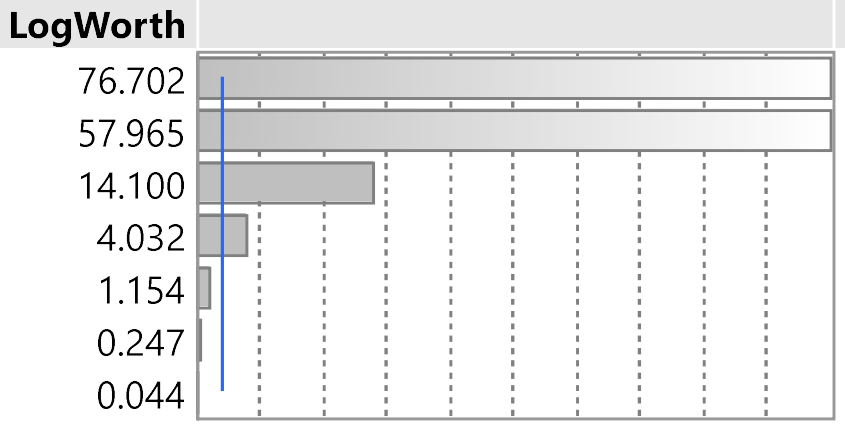

PValue

0.00000 0.00000 $0.00000 \wedge$ 0.00009 0.07013 $0.56584 \wedge$ $0.90268 \wedge$

Figure 8. The effect summary of the solubility of Compound X (Panel A) and Compound Y (Panel B) in biorelevant media with SLS. 

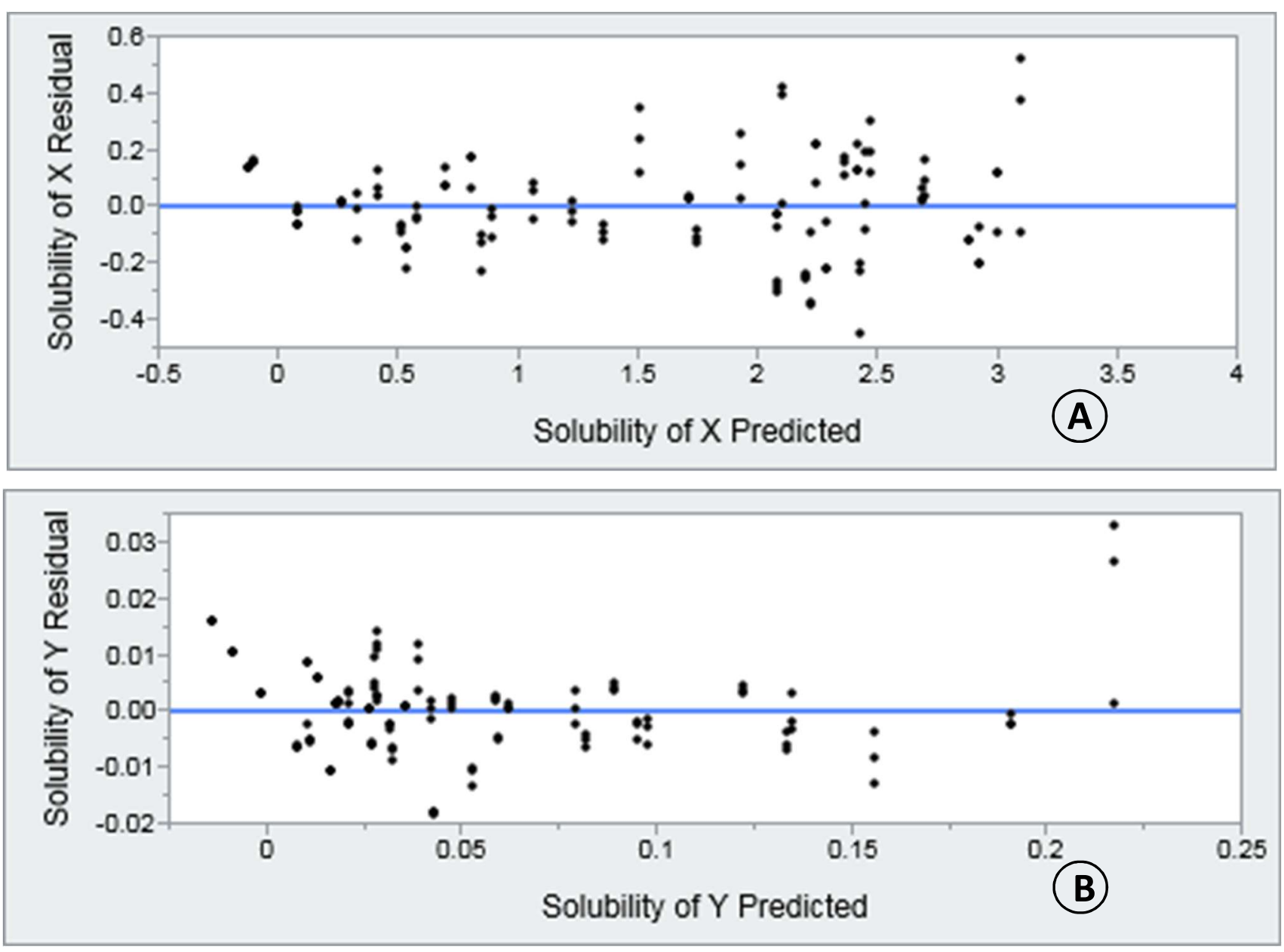

Figure 9. Residual plot of Compound X (Panel A) and Compound Y (Panel B) comparing the difference between the actual and model prediction.

Figure 10 shows the least squares means plots for the solubility of Compound $\mathrm{X}$ and Compound $\mathrm{Y}$ in various media investigated. The data shows a difference between the solubility obtained in different media, however for Compound X (Panel A) the difference between FaSSIF and FeSSIF, and also between SGF and water could not be easily identified. To determine the statistical difference between the media, a "contrast" analysis was applied. The contrast analysis between FaSSIF and FeSSIF produced a $\mathrm{p}$-value $=0.002$, indicating that the mean solubility of FaSSIF and FeSSIF are significantly different from each other. The contrast between SGF and water was also examined with a p- value $<0.001$. Overall, the analysis shows that the means of all four types of media are statistically different from each other.

For Compound Y solubility (Panel B), there was clearly an increasing trend of Compound Y solubility in the media with no overlapping of the standard deviation of the means. Inspection of the raw data in Figure 4 and Figure 6 also suggests that the slope of the solubility of Compound $\mathrm{Y}$ is different for each media type as a single agent and in combination with Compound $\mathrm{X}$. The table of effects confirms this with a p-value $<0.001$ for both the Media*SLS term and the Presence of Compound X*SLS term. 

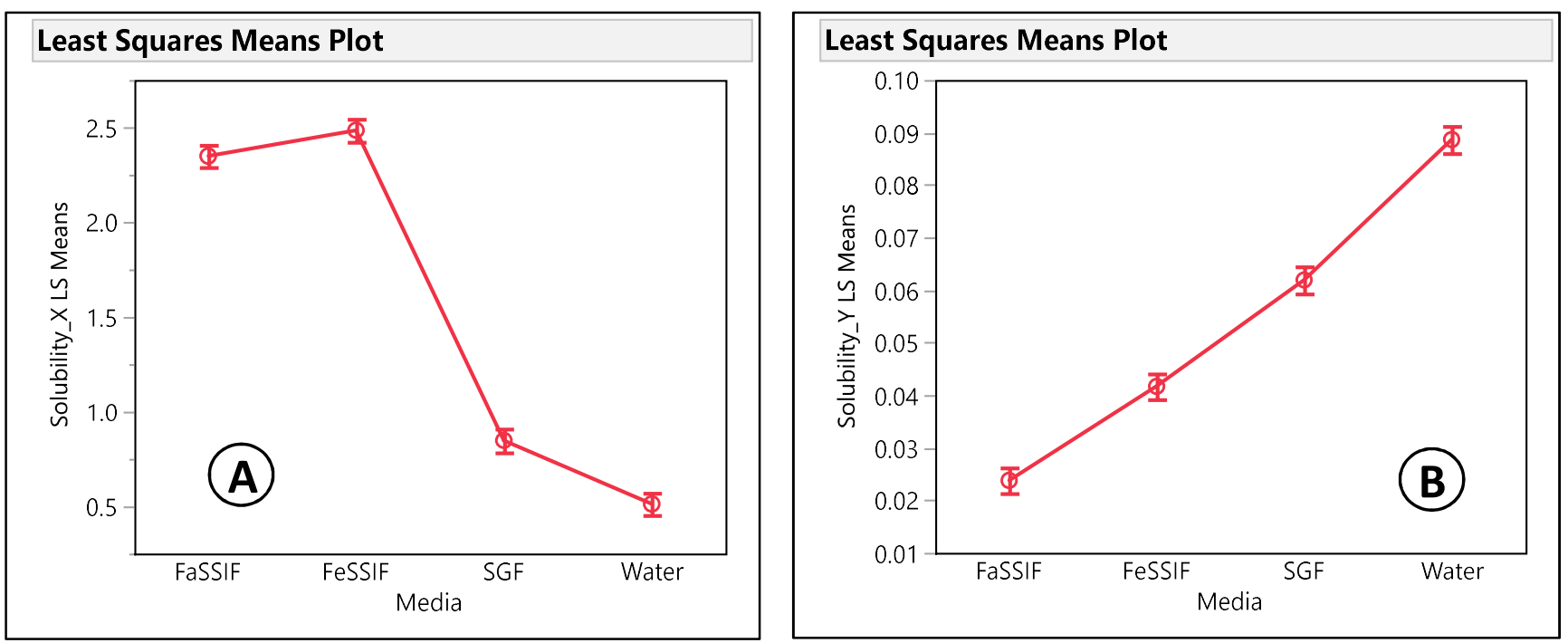

Figure 10. Least Squares Means plot of the solubility of Compound X (Panel A) and Compound Y (Panel B) as a factor of the various biorelevant media.

\section{IN-VITRO DISSOLUTION}

In-vitro dissolution was carried out with Compound $\mathrm{X}$ and Compound $\mathrm{Y}$ in the presence and absence of SLS using the dissolution method described in the Methods section. Figure 11 displays the release profile of Compound $\mathrm{X}$ both with and without the presence of SLS in the dissolution media. The data indicates that Compound $\mathrm{X}$ readily dissolves at the same rate with or without SLS and therefore SLS has no impact on the dissolution rate and/or the extent of dissolution based on the amount of Compound X (5 $\mathrm{mg}$ ) used in this analysis.

The release profiles of Compound $\mathrm{Y}$ in both the presence and absence of SLS in the dissolution media are presented in Figure 12. The data indicates that Compound $\mathrm{Y}$ does not have favorable wetting properties because in the absence of SLS in the dissolution media, only approximately $10 \%$ of Compound $\mathrm{Y}$ was dissolved. However, in the presence of SLS, full release of Compound Y was achieved in under 60 minutes.

\section{IN-VIVO DISSOLUTION AND ABSORPTION MECHANISTIC MODEL PREDICTION}

When an oral solid dosage drug form is ingested by a patient, there is a finite period of time during which drug absorption can occur. As the dosage form is swallowed, it begins to dissolve and release the drug while it passes into and through the stomach. The transit time is dependent on whether the patient has eaten food with their medication or not (34). In the fed state, transit time is several hours longer than in the fasted state. In addition to delayed gastric emptying, the gall bladder releases bile salts when the patient has fed, which can have a positive effect on drug solubility (35). If the drug is not absorbed through the gastric wall, then it will pass into the intestines where the more neutral $\mathrm{pH}$ may have a beneficial impact on drug dissolution and absorption. The presence of inert formulation excipients can sometimes have an effect on the solubility of certain compounds. In addition, it has been shown that certain components of simulated biorelevant media may form micelles which may enhance solubilization of a drug molecule (36).

Traditionally, aqueous drug solubility is used to predict behavior in the gastrointestinal tract. However, the lack of a buffering agent, and the absence of bile salts means that the reported aqueous solubility values are often not representative of invivo settings. Previous studies have shown that there is significant value in predicting drug behavior in simulated gastric and intestinal fluids (37). Generating automated solubility data using high throughput experimentation can lead to optimized mechanistic models to help predict drug dissolution. 


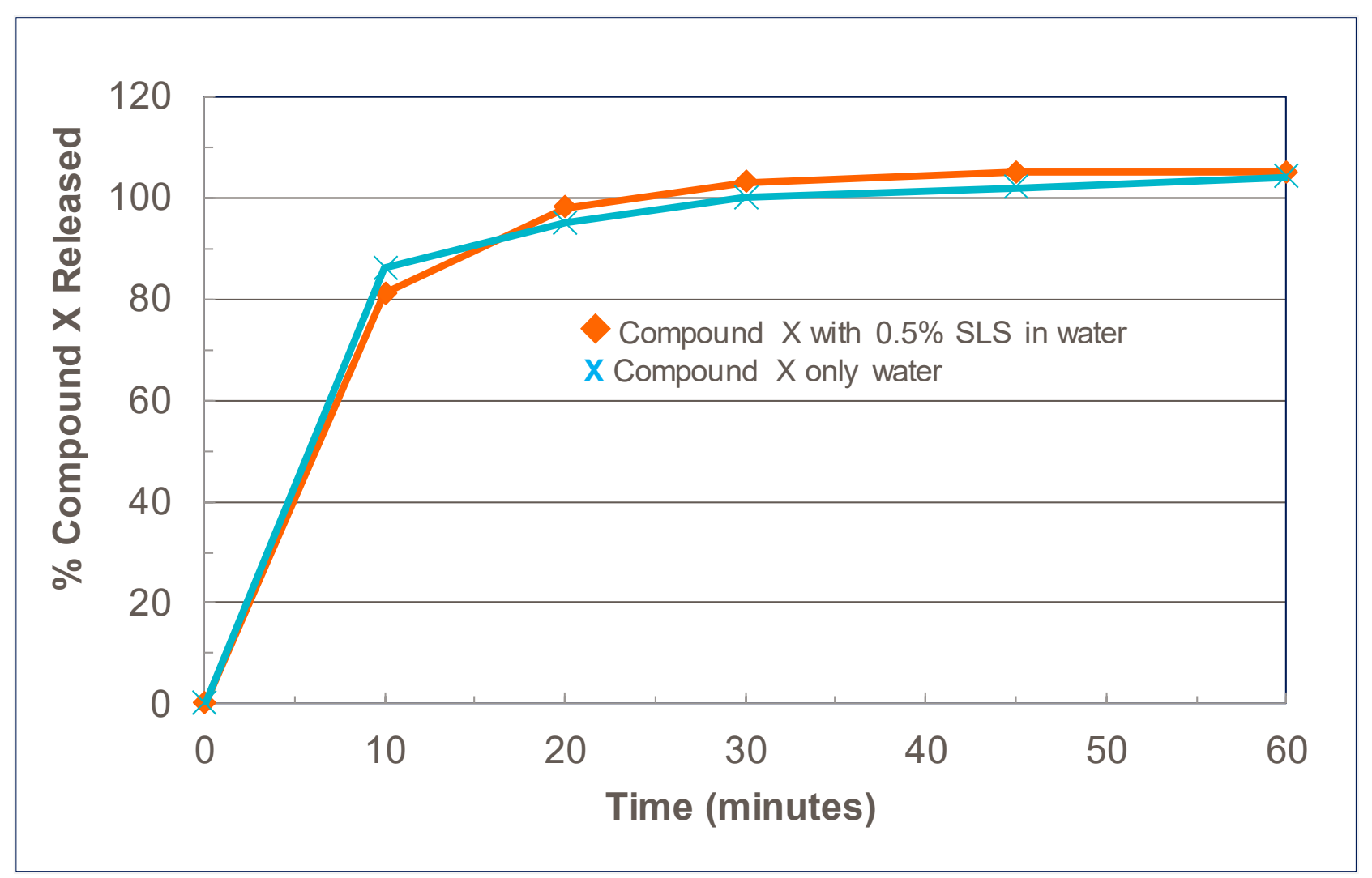

Figure 11. Dissolution profile of Compound $X$ with and without Sodium Lauryl Sulfate

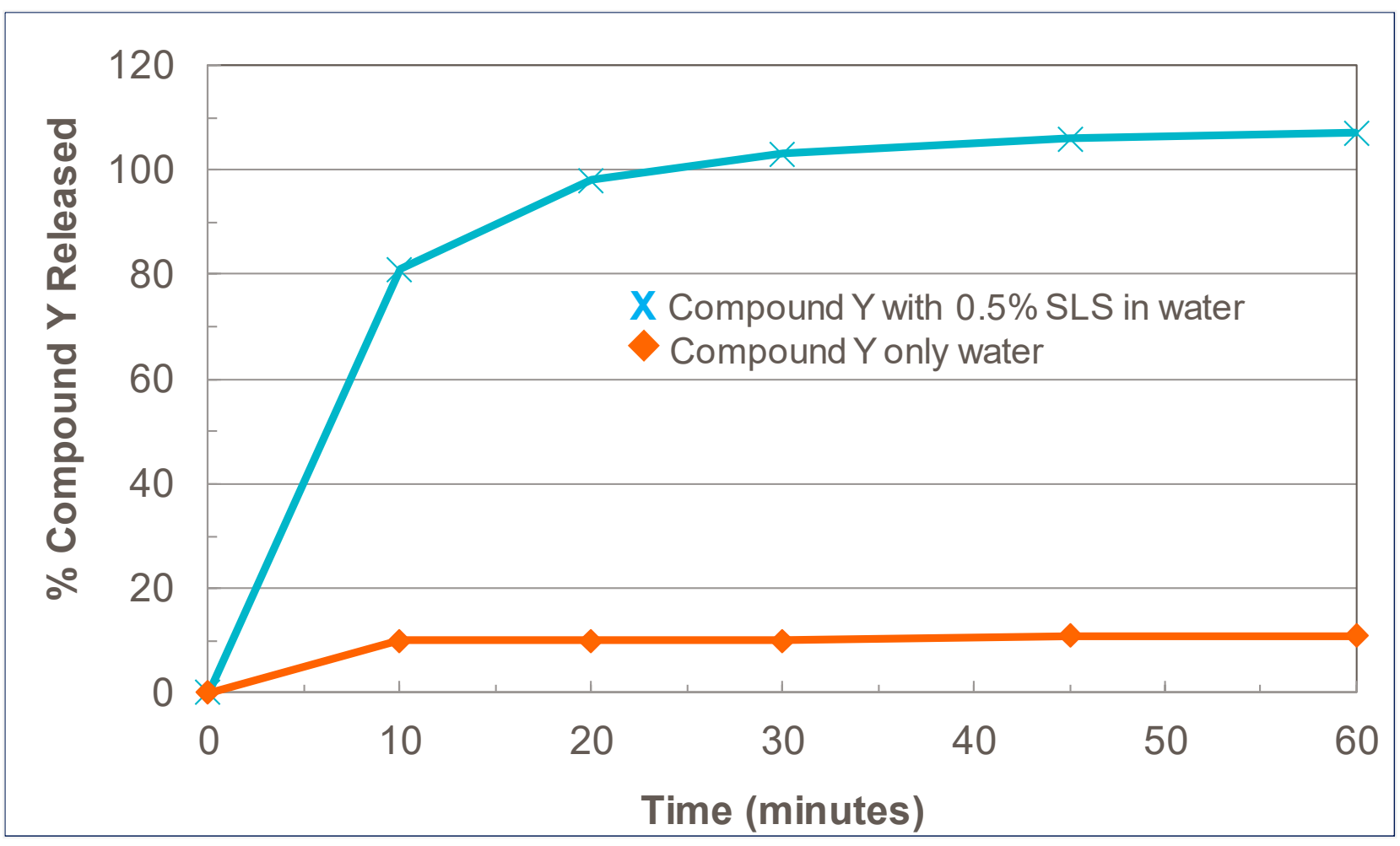

Figure 12. Dissolution profile of Compound $\mathrm{Y}$ with and without Sodium Lauryl Sulfate 
RATE AND EXTEND OF DISSOLUTION \& ABSORPTION, MECHANISTIC MODELING

\section{Compound $\mathrm{X}$}

The effects of SLS on the in-vivo dissolution and absorption of Compound $\mathrm{X}$ were modeled using gCOAS and are shown in Figure 13. Compound X is classified as a high permeability drug substance using in-vitro permeability studies in Caco-2 cells. The permeability was determined to be approximately $3 \times 10^{-4} \mathrm{~cm} / \mathrm{sec}$. Figure $13 \mathrm{~A}$ illustrates the in-vivo dissolution profiles of Compound $\mathrm{X}$ in the presence of different SLS concentrations. A slight increase in the rate of dissolution is observed with increasing amounts of SLS. This correlates with the higher solubility observed in the results of the automation experiments previously described. The extent of dissolution remained $100 \%$ but the dissolution rate increases with the increase with SLS concentration. Figure 13B shows the rate and extent of absorption for Compound $\mathrm{X}$ with varying concentrations of SLS and constant permeability. As expected, absorption profiles remained the same as the major fraction of Compound $\mathrm{X}$ was available for absorption (drug in solution). The dissolution process (Figure 13C) was rapid due to higher drug solubility observed in the presence of SLS. The differences in rate and extent of absorption was attributed to the differences in the permeability, as shown in Figure 13D.

\section{Compound Y}

Compound $\mathrm{Y}$ is classified as a high permeability drug substance using in-vitro permeability studies in Caco- 2 cells. The permeability was determined to be approximately $3 \times 10^{-4} \mathrm{~cm} / \mathrm{sec}$. Figure $14 \mathrm{~A}$ describes the in-vivo dissolution of Compound $\mathrm{Y}$ in the presence of increasing concentrations of SLS, whereby an increased rate of dissolution is observed. In the absence of SLS, the percent of drug dissolved is $5 \%$ at 8 hours. This indicates the solubility limited (38) dissolution for compound Y. In the presence of $1 \mathrm{mg}$ SLS, $55 \%$ of Compound $\mathrm{Y}$ is dissolved at 8 hours. This observation from modeling indicates the need to enhance the solubility to overcome a solubility-limited dissolution process $(39,40)$. In the presence of $2 \mathrm{mg}$ SLS, $100 \%$ of dissolution is observed within 2.5 hours. This trend, as observed in the model, continues with increasing amounts of SLS in the presence of Compound Y.
Figure 14B demonstrates the rate and extent of absorption of Compound $\mathrm{Y}$ with increasing amounts of SLS. Absorption profiles mimic the dissolution profile. $100 \%$ absorption was observed at concentrations at and above $2 \mathrm{mg}$ SLS. The effects of permeability on the in-vivo dissolution are shown in Figure 14C, and absorption of Compound Y are shown in Figure 14D.

\section{DISCUSSION}

The CMC of SLS in water and biorelevant media (SGF, and FeSSIF) in the presence of compounds $\mathrm{X}$ and $\mathrm{Y}$ were determined by UV absorbance. Statistical calculations of the variability in the UV absorbance measurements at each SLS concentration shows a significantly low standard deviation and variance, as can be observed in Figure 3. With no overlapping of the error bars from one media to another, the data presented in Figure 3 are statistically different. The maximum $\mathrm{CMC}$ values determined in the presence of Compound $\mathrm{X}$ were 4.0 $\mathrm{mM}, 1.3 \mathrm{mM}$, and $0.8 \mathrm{mM}$ in water, FeSSIF, and $\mathrm{SGF}$, respectively. The maximum CMC values determined in the presence of Compound $\mathrm{Y}$ were 4.6 $\mathrm{mM}, 2.0 \mathrm{mM}, 1.2 \mathrm{mM}$ in water, FeSSIF, and SGF, respectively (ref. Table 4). The difference in CMC values between compounds $\mathrm{X}$ and $\mathrm{Y}$ is most likely attributed to the difference in physicochemical properties between the two molecules. Compound $\mathrm{X}$ has a $\mathrm{pKa} \sim 4.0$ and thus there will be some degree of ionization of the molecule as a function of $\mathrm{pH}$, while Compound $\mathrm{Y}$ is a neutral molecule with no ionizable groups and will be uncharged across the physiological $\mathrm{pH}$ range. These differences resulted in the difference in the rate and extent of dissolution especially for Compound Y (ref. Figure 11 and Figure 12). The results of $p$-values comparing the average absorbance values of both Compound $\mathrm{X}$ and Compound $\mathrm{Y}$ in the different media using the student t-test indicated that it is unlikely that the obtained differences between the average absorbance for the samples of both Compound $\mathrm{X}$ and Compound $\mathrm{Y}$ in the different media occurred by chance and the difference in the average absorbance most likely exists in the populations from which it was drawn. In general, above the CMC the average absorbance values were significantly difference in the comparison using the student $\mathrm{t}$-test $\mathrm{p}<0.05$. 


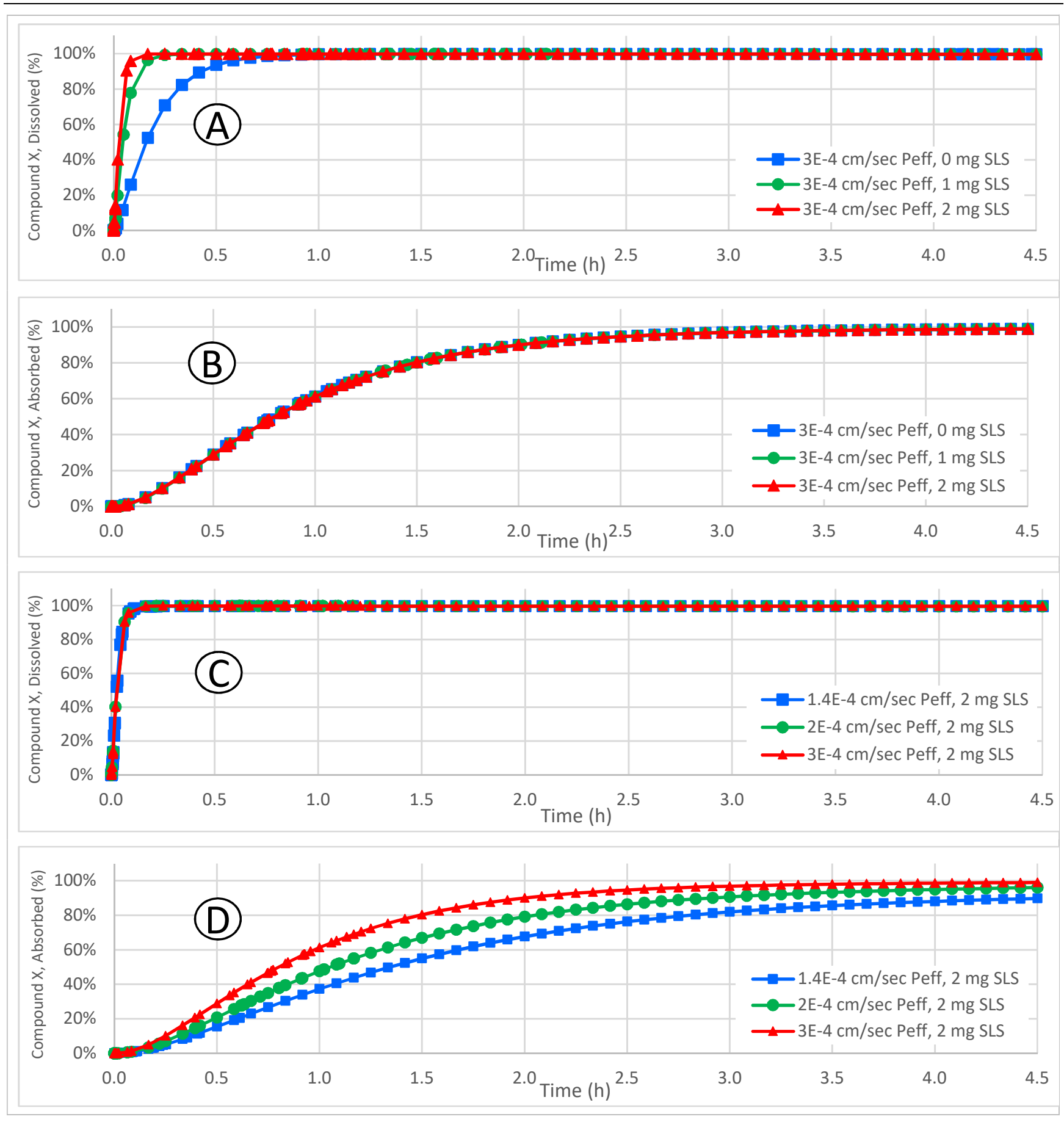

Figure 13. In-Vivo Mechanistic Absorption Simulation Model for Compound X.

Panel A: Effect of SLS concentration on the in vivo dissolution of Compound X

Panel B: Effect of SLS concentration on the rate and extent of absorption of Compound X

Panel C: Effect of permeability ( $\left.\mathrm{P}_{\text {eff }}\right)$ on Compound $\mathrm{X}$ dissolution with $2 \mathrm{mg}$ SLS

Panel D: Effect of permeability $\left(\mathrm{P}_{\mathrm{eff}}\right)$ on Compound $\mathrm{X}$ absorption with $2 \mathrm{mg}$ SLS 


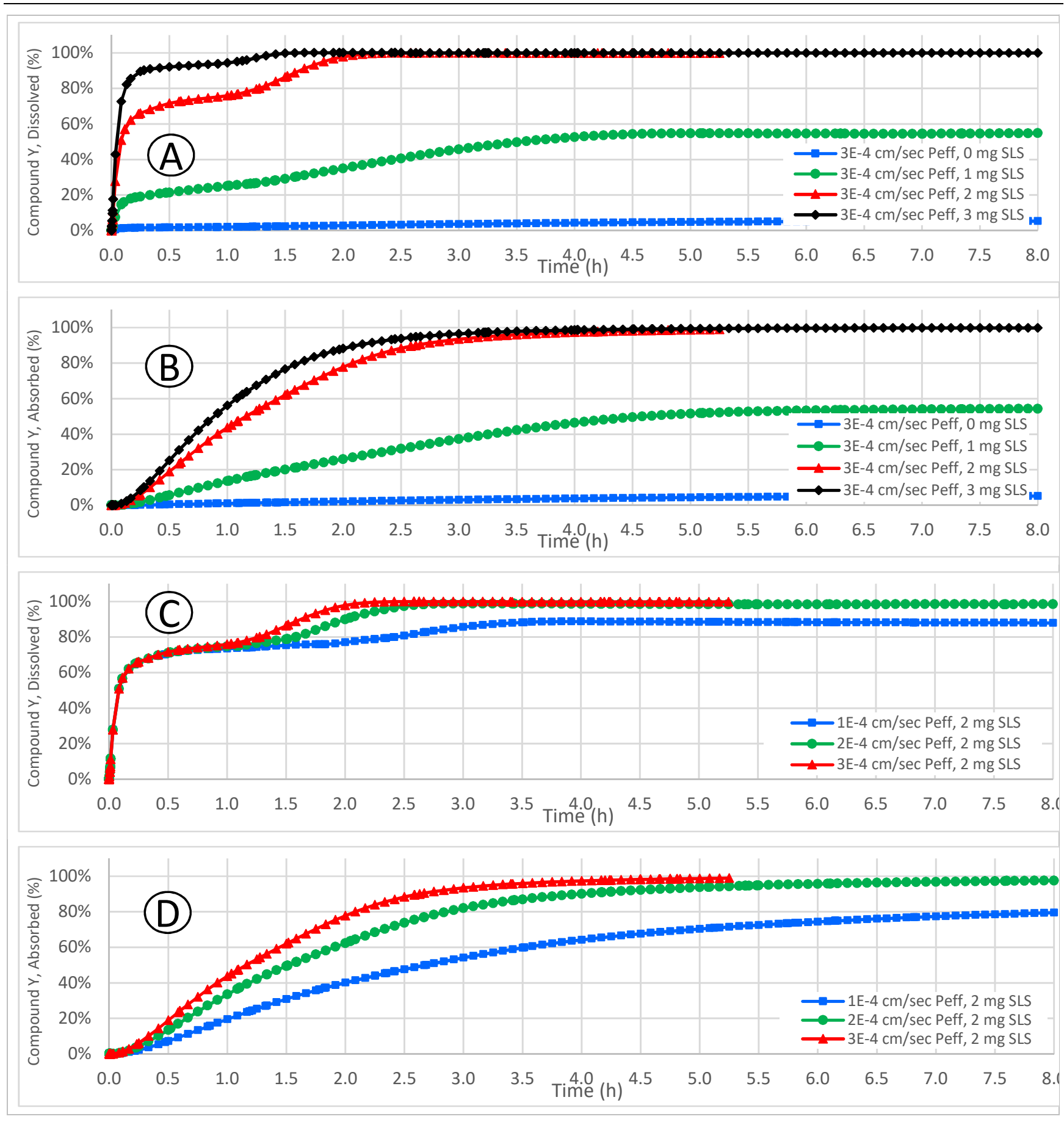

Figure 14. In-Vivo Mechanistic Absorption Simulation Model for Compound Y.

Panel A: Effect of SLS concentration on the in vivo dissolution of Compound Y

Panel B: Effect of SLS concentration on the rate and extent of absorption of Compound Y

Panel C: Effect of permeability $\left(\mathrm{P}_{\text {eff }}\right)$ on Compound Y dissolution with $2 \mathrm{mg}$ SLS

Panel D: Effect of permeability $\left(\mathrm{P}_{\text {eff }}\right)$ on Compound $\mathrm{Y}$ absorption with $2 \mathrm{mg}$ SLS 
The CMC of SLS in the presence of Compound $\mathrm{Y}$ is greater in all evaluated media compared to Compound X. In the scope of this manuscript, the explanation for the differences in $\mathrm{CMC}$ between compounds $\mathrm{X}$ and $\mathrm{Y}$ is mainly theoretical. In the presence of FeSSIF and water, Compound $\mathrm{X}$ will have mixed species (mostly ionized, and some unionized) as the $\mathrm{pH}>\mathrm{pKa}$ and thus will partition more favorably into the SLS micelles and requires less SLS to cause aggregation and micellization. On the other hand, Compound $\mathrm{Y}$ in the presence of FeSSIF and water is neutral and will potentially require higher SLS concentrations for micellization due to the non-ionic micellular core. In the acidic $\mathrm{pH}$ range below 4.0, both compounds $\mathrm{X}$ and $\mathrm{Y}$ will be uncharged. Therefore, it is the structural configuration and elemental constituent of the molecules which play a major role in the aggregation and micellization of SLS. Additionally, the larger magnitude of the slopes after the CMC in water, FeSSIF, and SGF for Compound $\mathrm{X}$ compared to Compound $\mathrm{Y}$ is an indication of the stronger aggregation of the micelles (ref. Figure 3). Also, the stronger aggregation for the micelles with Compound $\mathrm{X}$ has resulted in a higher solubility compared to Compound $\mathrm{Y}$ in all media investigated (water, SGF, FeSSIF and FaSSIF) (ref. Figure 4 and Figure 5).

As a combination oral product, the automation solubility data (ref. Figure 6 and Figure 7) indicated that the maximum solubility of both Compound $\mathrm{X}$ and Compound $\mathrm{Y}$ in stomach $\mathrm{pH}$ (SGF) was achieved with $2 \mathrm{mg}$ of SLS. Therefore, in designing a fixed dose combination (FDC) oral solid dosage form containing both Compound $\mathrm{X}$ and Compound Y, $2 \mathrm{mg}$ of SLS would be preferred to ensure maximum dissolution in the stomach and ultimately an increase in intestinal absorption. On the other hand, for a monotherapy oral solid dosage product, the automation solubility data indicated that a larger amount of SLS is required for maximum dissolution of both Compound $\mathrm{X}$ and Compound $\mathrm{Y}$ in SGF. From the data generated, $4 \mathrm{mg}$ of SLS gave the highest solubility of the compounds in all the media investigated. The ANOVA results indicated that solubility of Compound X was more impacted by the type of media than SLS concentration and Compound $\mathrm{Y}$ was more impacted by SLS concentration than the type of media due to the lower $\mathrm{p}$-value. Although the data indicates that there is a profound interaction between SLS concentration and media on both the solubility of Compound $\mathrm{X}$ and
Compound $Y$, there is no practical significance of the interaction because this interaction will be present in-vivo. Thus, the most important effect is that the solubility of both Compound $\mathrm{X}$ and Compound $\mathrm{Y}$ increases with the increase in SLS concentration in each of the media evaluated.

The mechanistic absorption model of the in-vivo performance for both compounds $\mathrm{X}$ and $\mathrm{Y}$ have provided very useful scientific insight into the impact of SLS concentrations and drug absorption. The simulation model indicated that due to the high solubility of Compound $\mathrm{X}$ in the lower gastrointestinal (GI) tract, the presence of SLS only slightly increased the rate of dissolution with no impact on the extent of dissolution (reference Figure 13A). Also, there was no impact on the oral absorption of Compound X in the presence of SLS due to its higher solubility in the lower GI tract and therefore the major fraction of Compound $\mathrm{X}$ was available for absorption (high percent of drug in solution), see Figure 13B. Additionally, the simulated modeling data indicated that if the permeability was to vary from the actual value (Figure 13C), then there would be no impact on the dissolution profile of Compound $\mathrm{X}$, which is most likely due to the higher rate of dissolution compared to the rate of absorption. On the other hand, if permeability decreases from the actual value, then the simulation model predicts a decrease in the rate and extent of absorption, as illustrated in Figure 13D. This is an expected result, because the higher solubility of Compound $\mathrm{X}$ in the lower GI tract means that a large amount of solubilized drug will always be available for absorption and is only limited by the permeability.

For Compound $\mathrm{Y}$, the in-vivo mechanistic simulation model predicts a significant impact of SLS concentration on the rate and extent of drug dissolution. The data indicates that the 100\% dissolution can be reached within the GI tract if at least $2 \mathrm{mg}$ of SLS is used in the oral solid dosage formulation, reference Figure 14A. The significant influence of SLS concentration on dissolution also translated into a similar impact on absorption. As can be seen in Figure 14B, 100\% absorption is only achieved with at least $2 \mathrm{mg}$ of SLS. This is due to the low intrinsic solubility of Compound Y across the GI $\mathrm{pH}$ as a result of the unionized/hydrophobic nature of the molecule. Furthermore, if the permeability of Compound $\mathrm{Y}$ is varied from the actual value, the simulation model predicts that the extent of dissolution was impacted at $2 \mathrm{mg}$ of SLS. 
Permeability of the drug can influence the sink conditions generated in-vivo because the lower the permeability, the slower the drug is removed from the system and therefore, the lower the extent of dissolution. At higher permeability, the sink conditions are maintained which allows the drug to maintain the dissolution rate and results in a high extent of dissolution (ref. Figure 14C). Varying the permeability in the simulation model indicated that the rate and extent of absorption will be impacted (ref. Figure 14D). The lower the permeability, the slower the drug is absorbed across the GI walls. Because the in-vivo system is transient with a finite time period in each of the GI compartments, the extent of absorption increases with an increase in permeability. Overall the in-vivo simulation model results demonstrated that increasing the SLS concentration will increase the dissolution rate of Compound $\mathrm{X}$ with no impact on the extent of dissolution. Also, the presence of SLS did not influence the absorption of Compound $\mathrm{X}$ due to its rapid dissolution rate. While for compound $\mathrm{Y}$, increasing SLS concentration increases both the rate and extent of dissolution as well as the rate and extent absorption. It is worth noting that SLS has no impact on the permeability of Compound $\mathrm{X}$ or Compound Y. The SLS concentration influences the rate and extent of dissolution, which then impacts the amount of drug absorbed and the absorption rate.

\section{CONCLUSION}

In this investigation, we have shown that the use of SLS in an oral solid dosage forms can increase the aqueous solubility of poorly water-soluble drug substances. The critical micelle concentration of SLS in water, SGF, and FeSSIF in the presence of poorly water-soluble model Compound $\mathrm{X}$ and Compound $\mathrm{Y}$ was determined using UV-Visible spectrophotometry. The micelles formed by SLS is a spontaneous process as shown by the negative values of the standard free energy of micellization. The critical micelle concentration of SLS in the various media investigated in the presence of compounds $\mathrm{X}$ and $\mathrm{Y}$ decreases in the following order: water> FeSSIF $>$ SGF. However, the aggregation of SLS in the various media is overall more spontaneous in the following order: $\mathrm{SGF}>\mathrm{FeSSIF}>$ water. Using high throughput experimentation and in-vivo mechanistic modeling, it was determined that a combination oral solid dosage product of compounds $\mathrm{X}$ and $\mathrm{Y}$ will have optimum solubility and in-vivo absorption if 2 $\mathrm{mg}$ of SLS was used in the solid dosage form. On the other hand, the solubility of individual compounds in the solid dosage form was shown to increase with increased levels of SLS in each of the media investigated. The results obtained from this study will help broaden the understanding of the micellization process involving SLS and poorlywater soluble drugs used in a combination oral solid dosage form. Also, it may help in designing the right level of experimentation and application of the right techniques to better understand and determine the optimum level of surfactant to use in a single-drug oral solid product and a fixed dose combination oral solid product.

\section{ACKNOWLEDGEMENTS}

The authors would like to thank Aakankschit Nandkeolyar from Drexel University for his support in providing transcription checking and statistical analysis.

\section{AUTHOR CONTRIBUTIONS}

The manuscript was written through contributions of all authors. All authors have given approval to the final version of the manuscript.

\section{REFERENCES}

1. Amidon GL, Lennernas H, Shah VP, Crison JR. A theoretical basis for a biopharmaceutic drug classification: The correlation of in vitro drug product dissolution and in vivo bioavailability. Pharmaceutical Research. 1995;12(3):413-20.

2. Yu LX, Amidon GL, Polli JE, Zhao H, Mehta MU, Conner DP, et al. Biopharmaceutics classification system: the scientific basis for biowaiver extensions. Pharm Res. 2002;19(7):921-5.

3. Wu CY, Benet LZ. Predicting drug disposition via application of BCS: Transport/absorption/ elimination interplay and development of a biopharmaceutics drug disposition classification system. Pharmaceutical Research. 2005;22(1):11-23.

4. Prentis RA, Lis Y, Walker SR. Pharmaceutical innovation by the seven UK-owned pharmaceutical companies (1964-1985). British Journal of Clinical Pharmacology. 1988;25(3):387-96.

5. Loftsson T, Brewster ME. Pharmaceutical applications of cyclodextrins: basic science and product development. Journal of Pharmacy and Pharmacology. 2010;62(11):1607-21.

6. Singh A, Worku ZA, Van den Mooter G. Oral formulation strategies to improve solubility of poorly 
water-soluble drugs. Expert Opinion on Drug Delivery. 2011;8(10):1361-78.

7. Liversidge GG, Cundy KC. Particle size reduction for improvement of oral bioavailability of hydrophobic drugs: I. Absolute oral bioavailability of nanocrystalline danazol in beagle dogs. International Journal of Pharmaceutics. 1995;125(1):91-7.

8. Khadka P, Ro J, Kim H, Kim I, Kim JT, Kim H, et al. Pharmaceutical particle technologies: An approach to improve drug solubility, dissolution and bioavailability. Asian Journal of Pharmaceutical Sciences. 2014;9(6):304-16.

9. Ware EC, Lu DR. An Automated Approach to Salt Selection for New Unique Trazodone Salts. Pharmaceutical Research. 2004;21(1):177-84.

10. Schultheiss N, Henck J-O. Chapter 6 Role of Cocrystals in the Pharmaceutical Development Continuum. Pharmaceutical Salts and Co-crystals: The Royal Society of Chemistry; 2012. p. 110-27.

11. Thompson DO. Cyclodextrins--enabling excipients: their present and future use in pharmaceuticals. Critical reviews in therapeutic drug carrier systems. 1997;14(1):1-104.

12. Fleisher D, Bong R, Stewart BH. Improved oral drug delivery: solubility limitations overcome by the use of prodrugs. Advanced Drug Delivery Reviews. 1996;19(2):115-30.

13. Pouton CW. Lipid formulations for oral administration of drugs: non-emulsifying, selfemulsifying and 'self-microemulsifying' drug delivery systems. European journal of pharmaceutical sciences : official journal of the European Federation for Pharmaceutical Sciences. 2000;11 Suppl 2:S93-8.

14. Serajuddin AT. Solid dispersion of poorly watersoluble drugs: early promises, subsequent problems, and recent breakthroughs. Journal of pharmaceutical sciences. 1999;88(10):1058-66.

15. Janssens S, Van den Mooter G. Review: physical chemistry of solid dispersions. The Journal of pharmacy and pharmacology. 2009;61(12):1571-86.

16. Ellenberger DJ, Miller DA, Williams RO, 3rd. Expanding the Application and Formulation Space of Amorphous Solid Dispersions with KinetiSol(R): a Review. AAPS PharmSciTech. 2018;19(5):1933-56.

17. Hanada M, Jermain SV, Lu X, Su Y, Williams RO, 3rd. Predicting physical stability of ternary amorphous solid dispersions using specific mechanical energy in a hot melt extrusion process. Int J Pharm. 2018;548(1):571-85.

18. Hanada M, Jermain SV, Williams RO, 3rd. Enhanced Dissolution of a Porous Carrier-Containing Ternary Amorphous Solid Dispersion System Prepared by a Hot Melt Method. Journal of pharmaceutical sciences. 2018;107(1):362-71.

19. Gursoy RN, Benita S. Self-emulsifying drug delivery systems (SEDDS) for improved oral delivery of lipophilic drugs. Biomedicine \& pharmacotherapy =
Biomedecine \& pharmacotherapie. 2004;58(3):17382.

20. Pouton CW. Formulation of poorly water-soluble drugs for oral administration: Physicochemical and physiological issues and the lipid formulation classification system. European Journal of Pharmaceutical Sciences. 2006;29(3):278-87.

21. Padrela L, Rodrigues MA, Velaga SP, Matos HA, de Azevedo EG. Formation of indomethacin-saccharin cocrystals using supercritical fluid technology. European journal of pharmaceutical sciences : official journal of the European Federation for Pharmaceutical Sciences. 2009;38(1):9-17.

22. Dahan A, Hoffman A. Rationalizing the selection of oral lipid based drug delivery systems by an in vitro dynamic lipolysis model for improved oral bioavailability of poorly water soluble drugs. Journal of controlled release : official journal of the Controlled Release Society. 2008;129(1):1-10.

23. Nazzal S, Nutan M, Palamakula A, Shah R, Zaghloul AA, Khan MA. Optimization of a selfnanoemulsified tablet dosage form of Ubiquinone using response surface methodology: effect of formulation ingredients. Int J Pharm. 2002;240(12):103-14

24. Hsieh AG, Punckt C, Korkut S, Aksay IA. Adsorption of Sodium Dodecyl Sulfate on Functionalized Graphene Measured by Conductometric Titration. The Journal of Physical Chemistry B. 2013;117(26):7950-8.

25. van Breemen RB, Li Y. Caco-2 cell permeability assays to measure drug absorption. Expert opinion on drug metabolism \& toxicology. 2005;1(2):175-85.

26. Sugano K, Okazaki A, Sugimoto S, Tavornvipas S, Omura A, Mano T. Solubility and dissolution profile assessment in drug discovery. Drug metabolism and pharmacokinetics. 2007;22(4):225-54.

27. Sugano K. Introduction to computational oral absorption simulation. Expert opinion on drug metabolism \& toxicology. 2009;5(3):259-93.

28. Takano R, Sugano K, Higashida A, Hayashi Y, Machida M, Aso Y, et al. Oral absorption of poorly water-soluble drugs: computer simulation of fraction absorbed in humans from a miniscale dissolution test. Pharm Res. 2006;23(6):1144-56.

29. Sugano K. Theoretical comparison of hydrodynamic diffusion layer models used for dissolution simulation in drug discovery and development. Int J Pharm. 2008;363(1-2):73-7.

30. Bhardwaj V, Sharma P, Chauhan MS, Chauhan S. Micellization, interaction and thermodynamic study of butylated hydroxyanisole (synthetic antioxidant) and sodium dodecyl sulfate in aqueous-ethanol solution at 25,30 and $35^{\circ} \mathrm{C}$. Journal of Saudi Chemical Society. 2016;20:S109-S14.

31. Pal A, Chaudhary S. Ionic liquids effect on critical micelle concentration of SDS: Conductivity, 
fluorescence and NMR studies. Fluid Phase Equilibria. 2014;372:100-4.

32. Alhmoud H, Ibrahim NE, El-Hallous E. Surfactants Solubility, Concentration and the other Formulations Effects on the Drug Release Rate From a ControlledRelease Matrix2014. 364 p.

33. Zheng W, Jain A, Papoutsakis D, Dannenfelser R-M, Panicucci R, Garad S. Selection of oral bioavailability enhancing formulations during drug discovery. Drug Development and Industrial Pharmacy. 2012;38(2):235-47.

34. Logan C. Use of Animals for the Determination of Absorption and Bioavailability. In: Mannhold, editor. Drug Bioavailability. Methods and Principles in Medicinal Chemistry2004. p. 132-54.

35. Jones HM, Parrott N, Ohlenbusch G, Lavé T. Predicting Pharmacokinetic Food Effects Using Biorelevant Solubility Media and Physiologically Based Modelling. Clinical Pharmacokinetics. 2006;45(12):1213-26.

36. Promzeleva M, Chislov M, Volkova T, Proshin A, Kumeev R, Terekhova I. Effects of Biorelevant Media Components on Dissolution Behaviour of
1,2,4-Thiadiazole Derivative Designed for Alzheimer's Disease Prevention. Chemistry \& Biodiversity. 2018;15(2):1-9.

37. Dressman JB, Vertzoni M, Goumas K, Reppas C. Estimating drug solubility in the gastrointestinal tract. Advanced Drug Delivery Reviews. 2007;59(7):591602.

38. Willmann S, Schmitt W, Keldenich J, Lippert J, Dressman JB. A physiological model for the estimation of the fraction dose absorbed in humans. Journal of medicinal chemistry. 2004;47(16):402231.

39. Dokoumetzidis A, Valsami G, Macheras P. Modelling and simulation in drug absorption processes. Xenobiotica; the fate of foreign compounds in biological systems. 2007;37(1011):1052-65.

40. Fagerberg JH, Tsinman O, Sun N, Tsinman K, Avdeef A, Bergström CAS. Dissolution Rate and Apparent Solubility of Poorly Soluble Drugs in Biorelevant Dissolution Media. Molecular Pharmaceutics. 2010;7(5):1419-30. 